\title{
Influence of the Substrate on the Formation of Metallic Glass Coatings by Cold Gas Spraying
}

John Henao, Amadeu Concustell, Sergi Dosta, Núria Cinca, Irene G. Cano, and Josep M. Guilemany

\author{
(Submitted February 9, 2016; in revised form April 9, 2016)
}

\begin{abstract}
Cold gas spray technology has been used to build up coatings of Fe-base metallic glass onto different metallic substrates. In this work, the effect of the substrate properties on the viscoplastic response of metallic glass particles during their impact has been studied. Thick coatings with high deposition efficiencies have been built-up in conditions of homogeneous flow on substrates such as Mild Steel AISI 1040, Stainless Steel 316L, Inconel 625, Aluminum 7075-T6, and Copper (99.9\%). Properties of the substrate have been identified to play an important role in the viscoplastic response of the metallic glass particles at impact. Depending on the process gas conditions, the impact morphologies show not only inhomogeneous deformation but also homogeneous plastic flow despite the high strain rates, $10^{8}$ to $10^{9} \mathrm{~s}^{-1}$, involved in the technique. Interestingly, homogenous deformation of metallic glass particles is promoted depending on the hardness and the thermal diffusivity of the substrate and it is not exclusively a function of the kinetic energy and the temperature of the particle at impact. Coating formation is discussed in terms of fundamentals of dynamics of undercooled liquids, viscoplastic flow mechanisms of metallic glasses, and substrate properties. The findings presented in this work have been used to build up a detailed scheme of the deposition mechanism of metallic glass coatings by the cold gas spraying technology.
\end{abstract}

Keywords coating, cold gas spray, deposition mechanisms, metallic glass, substrate effect

\section{Introduction}

Metallic glasses have garnered extensive interest in recent years due to their remarkable mechanical properties, excellent corrosion resistance, magnetic behavior, and unique processing capabilities, attributable to the lack of grain boundaries and crystal defects (Ref 1-3). Metallic glasses are used in a variety of applications such as in cell phone cases, golf clubs, watch and ornamental parts, as well as sensors, actuators, electromagnetic casting, and magnetic recording heads. Since the discovery of metallic glasses, different families have been developed based on the combination of more than 30 elements including transition metals, rare earth, and alkali elements (Ref 4-7). Among the different families of metallic glasses, Fe-base metallic glasses have attracted attention due to their relatively low-cost, good glass forming ability, high corrosion resistance, high compressive strength, excellent soft magnetic properties, and catalytic properties (Ref 2, 8, 9).

John Henao, Amadeu Concustell, Sergi Dosta, Núria Cinca, Irene G. Cano, and Josep M. Guilemany, Thermal Spray Centre (CPT), Universitat de Barcelona, C/ Martí Franqués 1, 08028 Barcelona, Spain. Contact e-mail: jhenao@cptub.eu.
The amorphous structure of metallic glasses provides them high strength, hardness, large elastic strains and enhanced corrosion and magnetic properties. However, the lack of a long-range ordered structure leads to a complex mechanism of plastic deformation including absence of strain hardening. Inhomogeneous deformation, i.e., localized plastic flow, is promoted at high strain rates and low temperatures, while homogeneous flow takes place at low strain rates and high temperatures (Ref 10). As a result, metallic glasses present limited plasticity at room temperature restricting their commercial proliferation. Different techniques have been proposed to overcome this drawback like promoting multiple shear band formation or homogeneous flow, and/or hindering shear band propagation. The fundamentals of these techniques consist in controlling sample size, composition of the glass, and the presence of a second crystalline phase (Ref 11). At small scales, metallic glasses exhibit enhanced plasticity and toughness, and they can be thermoplastically processed like polymer materials. The basis of forming a metallic glass coating from small-scale metallic glass particles is their enhanced processability at temperatures above the glass transition (Ref 10, 12). This allows to produce larger and complex parts, always keeping the mechanical and functional properties offered by metallic glasses.

Cold gas spray (CGS) coatings are mainly built-up on the basis of kinetic energy. The CGS system consists of a gas stream which is conducted through a converging diverging nozzle (De-Laval type nozzle) (Ref 13, 14). The gas is used to accelerate and transport particles up to the 
substrate, developing velocities in the range from 300 to $1200 \mathrm{~m} / \mathrm{s}$. The gas (typically $\mathrm{N}_{2}$ or $\mathrm{He}$ ) can be preheated and its pressure can be controlled in order to modify particle temperature and velocity at impact. Impact conditions consist in extreme strain rates, $10^{8}$ to $10^{9} \mathrm{~s}^{-1}$ and high cooling rates, $10^{5}$ to $10^{6} \mathrm{~K} / \mathrm{s}(\operatorname{Ref} 15,17)$. The particle temperature usually remains below the melting point of the material; for this reason CGS is known as a solid state process. Therefore, the coating is built-up by the plastic deformation of the impacting particles (Ref 12-19). For polycrystalline materials, the most important criterion for deposition is the so-called critical velocity (Ref 12, 19). The critical velocity is a parameter used to control and to predict the optimum deposition conditions of a given material, i.e., the range of proper temperatures and velocities of particles before impact. The deposition efficiency tendency follows a like-sigmoidal shape in function of the impact velocity of the process where high deposition efficiencies are obtained just above the critical velocity. The concept of critical velocity rises from ballistic expression of hydrodynamic penetration of particles at impact, combined with the Johnson-Cook model for softening of crystalline materials, which is often used for modeling and simulation of deforming metals (Ref 12, 19). In this manner, the conversion of kinetic energy, at conditions predicted by the critical velocity, results into plastic deformation and subsequent heat generation, localized at the impact region, promoting bonding at the interface particle/substrate (Ref 19-21).

On the other hand, metallic glasses, due to their amorphous nature, do not present strain-hardening and defects such as dislocations involved in the plasticity of crystalline materials (Ref 9, 22). In this manner, the concept based on the critical velocity results inappropriate since the softening of amorphous metals above the glass transition differs vastly from the Johnson-Cook model (Ref 28). For this reason, a good understanding of the mechanisms involving deformation in metallic glasses is required to develop any estimation of the optimum conditions for metallic glass deposition in CGS. Plasticity of metallic glasses is based in two different deformation modes: inhomogeneous flow (localized deformation by means of shear band formation) and homogeneous flow (non-localized deformation uniformly distributed). The type of flow is exclusively dependent on temperature and strain rate (Ref 9, 10, 22, 23). In this sense, previous studies, related with the production of metallic glass coatings by CGS (Ref 24-26), have been carried out under the concept of thermal softening between the glass transition temperature $\left(T_{\mathrm{g}}\right)$ and the crystallization temperature $\left(T_{\mathrm{x}}\right)$. Metallic glasses can deform homogenously between $T_{\mathrm{g}}$ and $T_{\mathrm{x}}$ and therefore, bonding is achieved more easily. However, preheating particles above $T_{\mathrm{g}}$ is not the unique requirement to deposit metallic glasses since their mechanical response is also dependent on the strain rates experienced at impact. At high strain rates and high temperatures, inhomogeneous flow can occur and poor deposition of metallic glass particles obtained (Ref 9, 22). In fact, it is well known that shear bands, i.e., inhomogeneous flow, are not only promoted at high strain rates and low temperatures, but they are also formed at temperatures around and above $T_{\mathrm{g}}$ if the strain rate is high enough (Ref 27). Recently, based on the equations governing the dynamics of undercooled liquids, the conditions for building up metallic glass coatings by CGS were redefined in terms of the Reynolds number $(R e)$ of the metallic glass in the supercooled liquid state. The $R e$ relates the inertial forces to the viscous forces acting throughout the metallic glass particle according to the following equation (Ref 28$)$.

$R e=\frac{\rho v_{0} d_{0}}{\mu}$

where $\rho, v_{0}, d_{0}$, and $\mu$ are the liquid density, the impacting particle velocity, the particle diameter, and the liquid viscosity, respectively. When the $R e$ is too small because of the large viscosity of the liquid, large elastic deformations are produced during impact leading either to rebounding or inhomogeneous deformation (shear band formation). This behavior is typically seen in nonNewtonian liquids undergoing yielding (Ref 27). These are conditions where metallic glass coatings are not able to grow-up. On the other hand, when the $R e$ overtakes a critical value, namely $R e_{\text {crit }}$, shear banding and elastic deformation are avoided, homogenous deformation is promoted, and high deposition efficiencies can be expected. The advantage of including the undercooled liquid properties using the $R e$ of metallic glasses lies in that the analysis can be extrapolated to different metallic glass systems. Interestingly, the formation of metallic glass coatings by CGS can be predicted by means of a window of deposition based on the $R e$, which is used to determine the ideal temperature and velocity range at which impacting particles are able to flow and building-up a metallic glass coating. The window of deposition of metallic glasses differs from the window of deposition of crystalline metallic coatings due to its amorphous nature itself in which the change of viscosity with temperature is exponential (Ref 28). In addition to homogeneous deformation, another condition to obtain metallic glass coatings is the suppression of the crystallization phenomena during the spraying process. Crystallization can hinder the deformation of particles at impact since mechanism involving viscous flow begins to be restricted by the atomic planes in the new crystal structure. Consequently, deposition efficiency deteriorates when crystallization occurs in metallic glasses (Ref 28, 29). In previous studies, the crystallization of the metallic glass particles could be totally avoided due to the high heating rate (around $1 \times 10^{6} \mathrm{~K} / \mathrm{s}$ ), the high cooling rate (around $1 \times 10^{5} \mathrm{~K} / \mathrm{s}$ ), and due to the control of the maximum temperature achieved by the particles during the CGS process (Ref 28). According to the classic theory of nucleation and growth (Ref 30), the crystallization is determined by the energy barrier for nucleation, the driving force for the liquidcrystal transformation, and the viscosity of the metallic glass. In overall, if the heating and cooling rates are fast enough to avoid the onset of crystallization of the metallic glass, the amorphous phase can be maintained during spraying process and in the final coatings. Therefore, the 
spraying conditions for deposition of metallic glass particles need a balance between high energetic conditions, in order to induce a $R e$ above $R e_{\text {crit }}$, and the kinetics of crystallization of the metallic glass.

Deposition of metallic glasses should be tackled not only from the above mentioned factors, but it must also be considered the contribution of the substrate material. It is known that impact-induced particle deformation depends on the mechanical properties of the substrate such as its elastic modulus and hardness (Ref 31). Previous CGS studies using crystalline particles suggest that particles undergo different strain rate conditions depending on the substrate hardness. The impact of a high velocity particle is classified according to the substrate/particle hardness as follows: similar hardness, softer substrate or harder substrate material. For example, a softer substrate leads to very low particle deformation and embedment. By contrast, a harder substrate promotes flattening and microstructural changes such as recrystallization (Ref 21, $32,33)$. In the case of crystalline metals, the characteristics of the substrate deformation affect bonding (Ref 31, 3437). Usually, bonding is promoted by shear instabilities at the particle/substrate interface (localized deformation and heat generation) (Ref 20,34). When the deformation of the substrate is low compared to the deformation of the particle, the shear instabilities are not formed at the interacting surfaces. Meanwhile, a larger deformation of the substrate can induce jet-type flow formation at the interacting surfaces (Ref 31, 34-38). Due to deformation, the flow of both materials promotes intimate contact which can result in metallurgical bonding (because flow of materials and heating favor atomic diffusion) and/or a good mechanical interlocking (flow favors anchoring) (Ref 31, 39). Just under conditions promoting shear instabilities, high deposition efficiencies are obtained. Up to date, the influence of the substrate on the deposition of metallic glasses by CGS has been barely tackled. Early studies suggest shear instabilities as the main mechanism acting on bonding and deposition of metallic glasses by CGS (Ref 40, 41); however, this argument has been based on models from crystalline metals, which are not relevant for metallic glasses. Regarding this fact, a complete study about bonding mechanisms and about the interaction between the metallic glass particle and the substrate still needs to be explored.

The thermal properties of the substrate material are also considered important for bonding of crystalline particles by CGS. Using numerical simulation, it has been demonstrated that thermal conduction might affect the deformation of both the particle and the substrate to some extent and hence the critical velocity in crystalline metal coatings (Ref 33). However, there is a sort of consensus suggesting that the heating induced by impacts of sprayed particles does not affect too much the particle deformation behavior and the impact process could be assumed to be adiabatic because the distances involved in the process are too small in comparison with the rate of heat dissipation (Ref 20, 21). That assumption could be reasonable for solid crystalline metals without induced softening, however for metals with a certain degree of softening and clearly for metallic glasses, the thermal interaction and rate of cooling might represent important changes in the behavior of these materials during deformation. In the particular case of metallic glasses, both mechanical and thermal properties of the substrate material might lead to changes in the $R e_{\text {crit }}$, and therefore the deposition efficiency could vary as substrate properties are changed.

This work explores the substrate influence on the deposition efficiency of Fe-base metallic glass coatings by CGS, and it shows a way to predict the building up conditions of coatings of any metallic glass by CGS regarding the intrinsic mechanical and thermal properties of both substrate and metallic glass particle. The effects of the mechanical properties of the substrate material on the deformation of metallic glass particles at impact have been studied based on ballistic expressions for plastic work, the law of conservation of energy, and considerations for a liquid in the undercooled state. Furthermore, experiments and numerical simulations have been carried out with aims of studying the thermal conduction interaction between particle and substrate at impact.

\section{Experimental Procedure}

Commercially available spherical Fe-base metallic glass powder of composition $\mathrm{Fe}_{72,8} \mathrm{Si}_{11,5} \mathrm{Cr}_{2,2} \mathrm{~B}_{10,7} \mathrm{C}_{2,9}$ at.\% (Kuamet 62B, Epson Atmix Corp, Japan) was sieved into a size distribution from 20 to $40 \mu \mathrm{m}$. A laser diffraction equipment (LS 13320 Laser Diffraction, Beckman Coulter, Inc., 250 S. Kraemer Blvd, Brea, CA) was used to verify the particle size distribution after sieving. X-ray diffraction (XRD) with a $\mathrm{Cu}-K \alpha$ radiation was employed to check the amorphous nature of the feedstock powder. Mild Steel AISI 1040, Stainless Steel 316 L, Aluminum7075-T6, commercially pure Copper (99.9\%) and Inconel625 plates with a flat geometry of $100 \times 50 \times 5 \mathrm{~mm}$ were used as substrate material. Plates were prepared by grinding using 240 grit $\mathrm{SiC}$ paper prior to spraying. The detailed process parameters used in this work for obtaining the Fe-base MG coatings are shown in Table 1. Two commercial CGS Systems: Kinetics ${ }^{\circledR}$ 4000/17 kW (Impact Innovations, Ampfing, Germany) with a maximum operating pressure of 40 bar and Impact 5/11 (Impact Innovations, Ampfing, Germany) with a maximum operating pressure of 50 bar were employed to deposit coatings using Nitrogen as carrier gas. A nozzle of type D24 WCCo and a pre-chamber extension of $43 \mathrm{~mm}$ were used. The traverse speed of the spraying gun was set as $250 \mathrm{~mm} / \mathrm{s}$, while the powder feeding rate was $42 \mathrm{~g} / \mathrm{min}$ during all experiments. The deposition efficiency was calculated measuring the final coating mass after spraying divided by the total sprayed powder mass onto the sample without overspray.

The $T_{\mathrm{g}}, T_{\mathrm{x}}$ and the crystallization enthalpy $\left(\Delta H_{\mathrm{x}}\right)$ of the initial powder and coatings were determined by differential scanning calorimetry (DSC) at a heating rate of $0.167 \mathrm{~K} / \mathrm{s}$ in a Mettler Toledo DSC1. Cross sections of the as-sprayed coatings were prepared for a metallographic 
Table 1 CGS process parameters for the different experiments carried out in this work

\begin{tabular}{|c|c|c|c|c|}
\hline Feedstock & Substrate & $\begin{array}{l}\text { Process gas } \\
\text { pressure, bar }\end{array}$ & $\begin{array}{c}\text { Process gas } \\
\text { temperature, }{ }^{\circ} \mathrm{C}\end{array}$ & $\begin{array}{c}\text { Stand-off } \\
\text { distance, } \mathbf{m m}\end{array}$ \\
\hline \multirow[t]{7}{*}{ Fe-base metallic glass powder } & 1040-steel316L-steel & 40 & 750 & 50 \\
\hline & Aluminum-7075-T6Inconel-625Copper (99.9\%) & 40 & 750 & 30 \\
\hline & & 40 & 800 & 50 \\
\hline & & 40 & 800 & 30 \\
\hline & & 40 & 800 & 10 \\
\hline & & 45 & 800 & 10 \\
\hline & & 50 & 800 & 10 \\
\hline
\end{tabular}

Table 2 Thermo-mechanical properties of the studied substrates (Ref 44$)$

\begin{tabular}{|c|c|c|c|c|c|c|}
\hline Property/material & Fe-base metallic glass & 1040-steel & 316L-steel & Inconel-625 & Aluminum-7075-T6 & Copper $(99.9 \%)$ \\
\hline Density, $\mathrm{kg} / \mathrm{m}^{3}$ & 7000 & 7845 & 7990 & 8440 & 2810 & 7940 \\
\hline Thermal conductivity, $\mathrm{W} /(\mathrm{m} \cdot \mathrm{K})$ & 10 & 50.7 & 16.3 & 9.8 & 130 & 360 \\
\hline Yield stress, $\mathrm{MPa}$ & $\ldots$ & 370 & 290 & 460 & 375 & 333 \\
\hline Elastic modulus, GPa & $146 *$ & 200 & 193 & 208 & 71.7 & 110 \\
\hline Hardness, Hv & $1100 *(10.79 \mathrm{GPa})$ & $178 *(1.75 \mathrm{GPa})$ & $175 *(1.72 \mathrm{GPa})$ & $330 *(3.24 \mathrm{GPa})$ & $155 *(1.52 \mathrm{GPa})$ & $100 *(0.98 \mathrm{GPa})$ \\
\hline
\end{tabular}

study according to the ASTM E3-01 standard. Cross section porosity of the MG coatings was measured according to ASTM E2109-01 standard and using the ImageJ software (Ref 42). Microstructure of the as-sprayed coatings and single impacts were studied using scanning electron microscopy (SEM). At least 100 single impacts were studied by sample, and measurements of the mean penetration depth $\left(\delta_{\exp }\right)$ and the mean aspect ratio were performed for each particle/substrate interface. The aspect ratio was calculated as the ratio of the total height of the particle post impact, $L_{\mathrm{y}}$, and the particle width post impact, $L_{\mathrm{x}}$, i.e., Aspect ratio $=L_{\mathrm{y}} / L_{\mathrm{x}}$, in this way Aspect ratio $=1$ is considered as no deformation.

With the aim of understanding the influence of the substrate material on the deformation and deposition of the metallic glass particles at impact, a one-dimensional and isentropic model for the gas flow was used in order to estimate the particle velocity and temperature just at the moment of impact. The model includes equations expressing the conservation of mass, momentum, and energy. Details of the process used to determine both velocity and temperature of the particle from the initial gas temperature and gas pressure by CGS are reported in detail in previous works (Ref 28, 39, 43). Particle temperature was employed to estimate the metallic glass viscosity according to the Vogel Fulcher Tamman (VFT) equation. VFT equation is commonly used to describe the equilibrium viscosity of metallic glasses over 15 orders of magnitude, i.e., from the melting point to the glass transition temperature. Details of the viscosity estimation for the present metallic glass composition are explained in (Ref 28). The particle velocity and viscosity were used to calculate the $R e$ of the Fe-base metallic glass particles at impact following Eq 1 for the different spraying conditions studied in this work. Finally, the study about the thermal interaction particle/substrate was carried out by means of the commercial software COMSOL multiphysics 3.5. The particle was supposed to impact in a direction normal to the substrate surface and the meshing was conducted using a 2D lagrange quadratic element. Vickers hardness measurements were performed in a microVickers indenter (Matsuzawa indenter MXT CX-1, Matsuzawa Co., Ltd, Akita-shi, Akita, Japan). At least, 10 indentations were collected on the polished surface of each substrate specimen setting a load of $500 \mathrm{gF}$ and dwell time of $10 \mathrm{~s}$. Nanoindentation technique was employed to evaluate the hardness $(\mathrm{H})$ and Young Modulus $(\mathrm{E})$ for metallic glass particles using a Berkovich indenter at $5 \mathrm{mN}$ load. Table 2 shows the material properties used in the present work (Ref 44).

\section{Results}

Figure 1(a) shows the particle morphology of the initial Fe-base metallic glass powder, and Fig. 1(b) the particle size distribution after sieving. The powder presents a spherical smooth surface typical from gas-atomized powders. The sieved Fe-base metallic glass powder has a micrometric particle size, with a portion of the powder between 25 and $40 \mu \mathrm{m}$ corresponding to a $72 \%$ in volume, according to Fig. 1(b). A $12 \%$ in volume is below $25 \mu \mathrm{m}$ and a $16 \%$ in volume of the powder is above $40 \mu \mathrm{m}$. The XRD analysis of the feedstock powder, Fig. 1(c), shows a broad halo typical in amorphous materials, while DSC measurements in Fig. 1(d) reveal an endothermic heat flux corresponding to the glass transition at $476{ }^{\circ} \mathrm{C}\left(T_{\mathrm{g}}\right)$ and an exothermic peak due to crystallization of the supercooled liquid at $561{ }^{\circ} \mathrm{C}\left(T_{\mathrm{x}}\right)$. DSC analysis, Fig. 2(a), also reveals that $\mathrm{Fe}$ base metallic glass coatings are totally amorphous when gas conditions are set from $\operatorname{Re}_{1}\left(750^{\circ} \mathrm{C} 40\right.$ bar $)$ to $\operatorname{Re}_{6}\left(800^{\circ} \mathrm{C} 45\right.$ bar $)$. However, crystallization takes place 

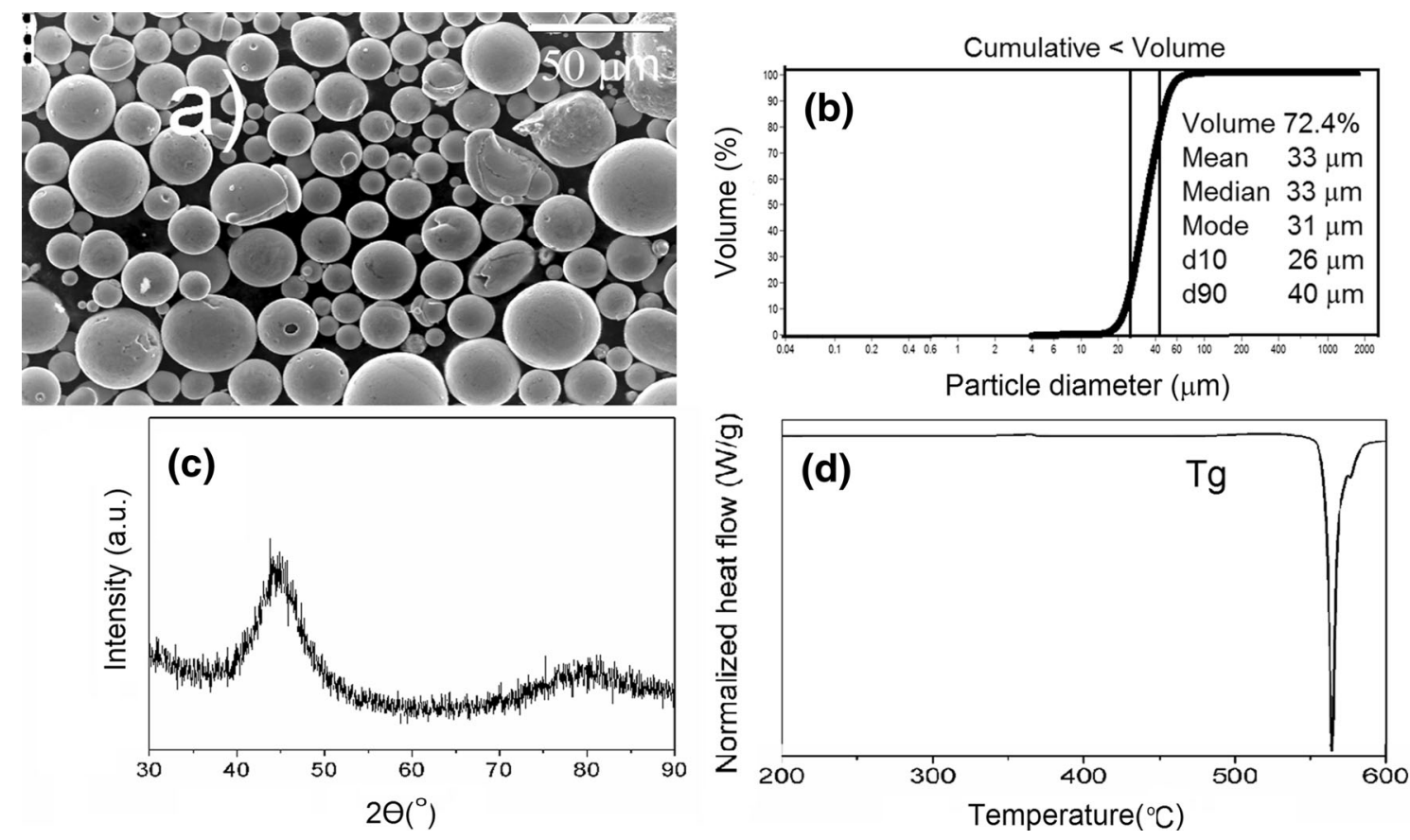

Fig. 1 Characteristics of the Fe-base metallic glass powder, (a) Surface morphology, (b) particle size distribution, the vertical lines show the range between $+25-40$ microns, (c) XRD pattern and (d) DSC scan of the initial powder

when the gas pressure is increased to 50 bar at $R e_{7}$, where the crystallization peak clearly changes. Figure 2(b) shows the crystallization enthalpy measured by DSC for the Febase $\mathrm{MG}$ coatings onto the different substrates at $\left(800{ }^{\circ} \mathrm{C}\right.$ 45 bar) $R e_{6}$ and $\left(800{ }^{\circ} \mathrm{C} 50\right.$ bar) $R e_{7}$, respectively. These results show that crystallization occurs in the metallic glass coatings at the highest pressure (50 bar) independently of the substrate used. In fact, early studies (Ref 28, 29) point out that crystallization of Fe-base metallic glass particles takes place during the particle flight according to the Johnson-Mehl-Avrami-Kolmogorov theory. In the present work, crystallization also takes place in-flight due to the high temperatures experienced by the particles inside the nozzle. Using the same procedure as (Ref 28, 45), the crystallized volume fraction ( $\left.V_{\text {crys }}\right)$ of each specimen has been estimated by normalizing the difference of crystallization enthalpy of the initial amorphous powder and the specimen by the enthalpy of crystallization of the amorphous powder. The $V_{\text {crys }}$ of the Fe-base metallic glass coatings sprayed at 50 bar is around $12 \%$, as determined from the data in Fig. 2(a) and (b).

Table 3 shows the $R e$ of the Fe-base metallic glass particle at the moment of impact for the different spraying conditions used in this work. According to the LS measurements, Fig. 1(b), estimations of $R e$ have been conducted using a mean particle diameter of $30 \mu \mathrm{m}$. Note that the $R e$ increases with gas temperature and gas pressure since both temperature and pressure promote variations in particle temperature, i.e., viscosity, and particle velocity. Figure 3 shows the deposition efficiency of the Fe-base metallic glass coatings onto the different substrates versus the $R e$. In all the cases, the deposition efficiency initially increases with increasing $R e$; however, three different behaviors are found depending on the substrates used. The first group of materials, the 1040-steel and 316L-steel, displays a sharp rise in deposition efficiency with increasing the $R e$, followed by a plateau of a maximum achievable deposition efficiency and finally, a decrease in the deposition efficiency when the $R e$ becomes too high. The second group consists of the Aluminum-7075-T6, the behavior is similar to the previous case, but the plateau is not present. Finally, coatings sprayed onto Copper (99. $9 \%$ ) and Inconel-625 alloys show a monotonical increase in the deposition efficiency until reaching a maximum at the largest $R e$ studied.

Cross section of the sprayed coatings onto 1040-steel for conditions corresponding from $R e_{1}$ to $R e_{7}$ has been investigated by SEM, Fig. 4, in order to reveal the differences in particle deformation. When the Re is too low, metallic glass particles deform in homogeneously, as shown in Fig. 4(a) and (b). Metallic glass particles present softening and their flattening becomes more severe as the $R e$ increases, Fig. 4(c) and (d). Particles present lateral viscous flow in the impact zone promoted by the high strain rates and low viscosity of the metallic glass at impact, see Fig. 4(e) and (f). When the viscosity reaches very low values, i.e., a large $R e$, metallic glass particles still deform homogenously; however, the formation of very thin sections by viscous deformation and the rapid cooling lead to their fracture by the new incoming particles, as shown in Fig. 4(g).

Cross section of the coatings obtained onto the different substrates has been also studied. Since the difference of deposition efficiency is especially notorious at low viscosities, cross section micrograph has been taken for coatings at $R_{5}$ conditions. Figure 5 shows the $\mathrm{Fe}$ base 

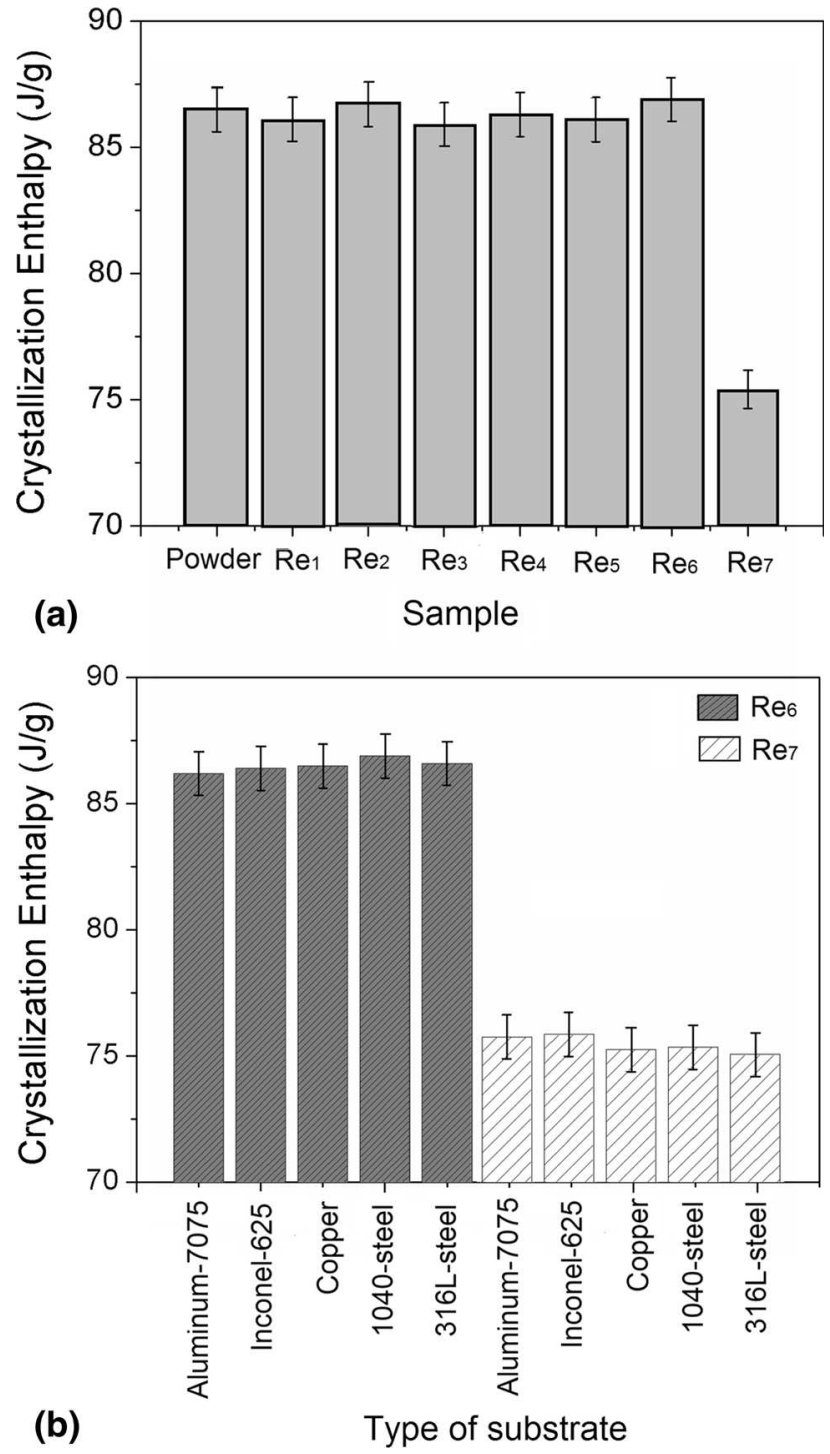

Fig. 2 (a) Crystallization enthalpy of the feedstock powder, and the coatings deposited onto 1040 -steel at different $R e$, i.e., spraying conditions shown in Table 3. (b) Crystallization enthalpy of the Fe-base metallic glass coatings at $R e_{6}$ and at $R e_{7}$ deposited onto the different studied substrates

metallic glass particles after impacting onto the surface of the different metallic substrates at $\operatorname{Re}_{5}$ conditions. Particles impacting onto Copper (99.9\%) and Aluminum-7075T6 undergo very low deformation and the penetration depth is in the order of the particle diameter. Particles impacting onto 1040-steel, 316L-steel and Inconel-625 show homogeneous deformation and they present low penetration depth.

Figure 6 shows the porosity of the Fe base metallic glass coatings according to the different studied metallic substrates. Porosity of the Fe base metallic glass coatings decreases as the $R e$ increases up to $R e_{6}$ for all cases, but it is interesting to note that it is higher in the case of coatings onto Aluminum-7075-T6 and Copper (99.9\%). When metallic glass coatings start to grow-up, the particle/par- ticle impact generates a compact structure in those cases where the particle/substrate impact promotes homogenous deformation. This is observed in metallic glass coatings sprayed onto 1040-steel, 316L-steel, and Inconel-625. In the case of the metallic glass coatings obtained onto Copper (99.9\%) and Aluminum-7075-T6, where the particle/substrate impact promotes inhomogeneous deformation, a porous structure is produced during the formation of the metallic glass coatings and therefore they have a higher porosity for identical spraying conditions. At $R e_{7}$, the porosity of the metallic glass coatings is the highest independently of the substrate. Interestingly, the increase of porosity after $R e_{5}$ matches with the results in Fig. 4(g). At this condition, small debris appears in the coatings as a consequence of the fracture of the jets formed in the metallic glass particles after impact contributing to the increase of the total porosity.

\section{Discussion}

\subsection{Impact Conditions in Metallic Glasses}

As shown in Fig. 3, small Re leads to low deposition efficiency because inhomogeneous deformation is promoted, see Fig. 4(a). Under these conditions, the viscosity of the metallic glass particles is high and they are not able to deform plastically during impact. Thus, metallic glass particles either bounce-off or break by means of shear band formation. However, the mechanism of deformation during impact changes at higher $R e$. As concluded in previous work (Ref 28), the deposition efficiency is superior to $50 \%$ just reached a given $R e$, namely $R e_{\text {crit. }}$ Above this $R e_{\text {crit }}$, the viscosity of the metallic glass is low enough to allow homogeneous deformation, coating growth, and good particle adhesion. The results in Fig. 3, 4 and 6 confirm this behavior. Note that the $R e_{\text {crit }}$ is different depending on the substrate material. Figure 3 allows measuring the $R e_{\text {crit }}$ for coatings sprayed onto 1040-steel, 316L-steel, Inconel-625, Aluminum 7075-T6, and Copper $(99.9 \%)$, and the results are $0.005,0.007,0.0131,0.0356$, and 0.054 , respectively. The variation in the $R e_{\text {crit }}$ should be related to the influence of both the mechanical properties and the thermal properties of the substrate material. A hard substrate leads to high strain rates, and thus, it could change the deformation mechanism of the metallic glass particle, while a material with high thermal diffusivity could quickly decrease the particle temperature and thus it could also affect its deformation mode as well.

In the case of Fe-base metallic glass coatings sprayed onto 1040-steel and 316L-steel, see Fig. 3, the plot deposition efficiency versus $R e$ follows a similar tendency than the plot ratio of bonds versus impact velocity in crystalline metal coatings deposited by CGS. In crystalline metal coatings, the deposition efficiency increases, reaches a maximum, presents a plateau, and finally decreases. Such drop in efficiency of crystalline metals is related to an increase in the rebound energy because of the high impact energy. This leads to the particle eroding the substrate material instead of building-up a coating (Ref 46). A 
Table $3 R e$ number and impact conditions calculated at the different studied spraying conditions

\begin{tabular}{lccccc}
\hline Gas pressure, bar & Gas temperature, ${ }^{\circ} \mathbf{C}$ & Stand-off distance, $\mathbf{~ m m}$ & $\boldsymbol{V}_{\mathbf{i m p}}, \mathbf{m} / \mathbf{s}$ & $\boldsymbol{T}_{\text {imp }},{ }^{\circ} \mathbf{C}$ & Re number(dimensionless) \\
\hline 40 & 750 & 50 & 595 & 527 & $R e_{1}=5.0 \mathrm{E}-5$ \\
40 & 750 & 30 & 532 & 549 & $R e_{2}=8.0 \mathrm{E}-4$ \\
40 & 800 & 50 & 607 & 570 & $R e_{3}=1.28 \mathrm{E}-2$ \\
40 & 800 & 30 & 546 & 592 & $R e_{4}=8.20 \mathrm{E}-2$ \\
40 & 800 & 10 & 516 & 628 & $R e_{5}=1.200$ \\
45 & 10 & 575 & 636 & $R e_{6}=2.319$ \\
50 & 10 & 644 & $R e_{7}=4.006$ \\
\hline
\end{tabular}

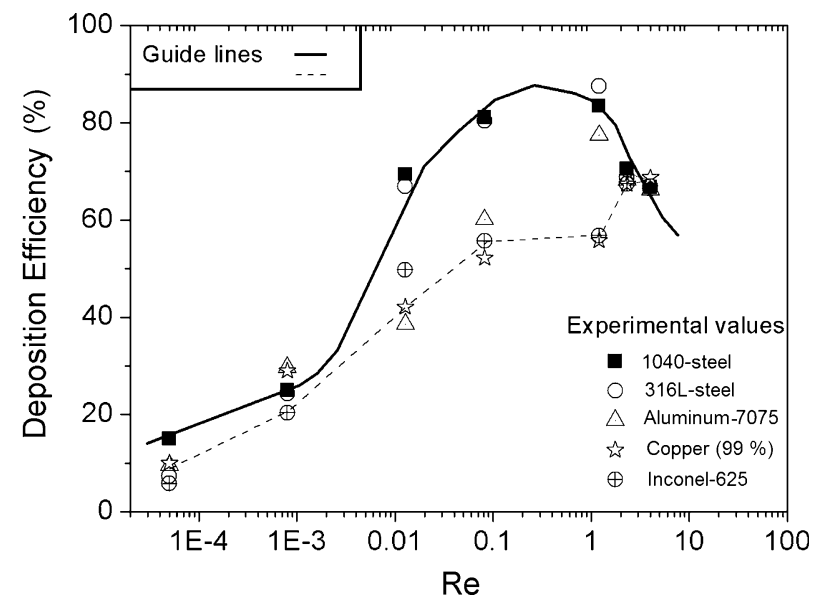

Fig. 3 Deposition efficiency in function of the Reynolds number for the different studied substrates. The continuous guide line follows the behavior presenting a maximum of deposition efficiency, whilst the discontinuous guide line shows the monotonical increase of deposition efficiency in Copper (99.9\%) and Inconel625

similar behavior has been observed for different metallic glass compositions (Fe-base, Ni-base and Cu-base) sprayed by CGS onto steel substrates. High energetic conditions (temperatures above the glass transition) led to improved deposition efficiency, although it was limited by erosion and/or excessive softening (Ref 26, 47, 48). The Fe base metallic glass composition studied in this work clearly shows a tendency to deform homogeneously when the $R e$ increases, see Fig. 4, even if the deposition efficiency decreases after a maximum value or increases monotonically as the sprayed coatings onto 1040-steel and 316L-steel or Inconel-625 and Copper (99.9\%), respectively. SEM micrographs in Fig. 4 also show particles experiencing fracture after impact at the largest $R e$, despite of homogenous deformation. The high porosity for deposited coatings at $R e_{7}$ condition is related to the breakup of the jets formed in the metallic glass particles after impact or to the excessive spreading of the particle itself due to its low viscosity, see Fig. 6. It is well known that splashing phenomenon can occur in liquids impacting with large $R e$. When a liquid drop undergoes splashing, the drop breaks into many droplets since either the shock energy is able to overcome the cohesion energy of the surface or the inertial viscous dissipation is not enough to dissipate the kinetic energy (Ref 49). In fact, previous studies suggest that metallic glass particles can fracture and bounce-off if they soften excessively (Ref 50). Under that condition, most of the deformation is concentrated in the metallic glass particle side and therefore the influence of the substrate on the coating formation is depleted. In this manner, the deposition efficiency decreases in the best of the cases (1040-steel, 316L-steel, Aluminum-7075-T6), and it increases in the others (Inconel-625, Copper $(99.9 \%))$ leading to the same deposition efficiency value independently of the substrate used. For coatings deposited onto Inconel-625 and Copper (99.9\%), the special mechanical and thermal properties of these substrate materials can be associated to the different behaviors of the deposition efficiency with respect to the other substrates, as discussed in the following section.

Particles of different sizes reach the surface at different temperatures and velocities; therefore, it is important to consider the $R e$ for different particle sizes. Figure 7 shows the $R e$ in terms of the spraying conditions and the particle size. One can note that the $R e$ increases as gas pressure and gas temperature are increased in all cases. Smaller particles $(25$ and $30 \mu \mathrm{m})$ present smaller $R e$ than the biggest ones in all conditions. As mentioned in the results section, the sprayed Fe-base metallic glass powder consisted of $72 \%$ in volume of particles in the range of 25 to $40 \mu \mathrm{m}$ with a mean particle size of $30 \mu \mathrm{m}$. Taking into account this particle size distribution, metallic glass particles below $35 \mu \mathrm{m}$ impact onto the substrate with a $R e$ smaller than $R e_{\text {crit }}$ at $750{ }^{\circ} \mathrm{C} 40$ bar, as represented by the dashed line at the bottom of Fig. 7 (deposited onto 1040steel). Under this condition, most of the metallic glass particles deform inhomogeneously and the contribution to the deposition efficiency is mainly due to the biggest particles $(>35 \mu \mathrm{m})$. At $800{ }^{\circ} \mathrm{C}$ and 40 bar, all particles impact at a $R e$ above the $R e_{\text {crit }}$, the smaller metallic glass particles present enough softening and contribute to improve the deposition efficiency as observed in Fig. 3 and 4. Increasing gas pressure (from 40 bar to 50 bar), the metallic glass particles deform excessively leading to subsequent fracture $\left(\operatorname{Re}_{7}\right)$, Fig. $4(\mathrm{~g})$. According to the mentioned above, $R e_{7}$ is taken as a reference for excessive softening. Therefore, the deposition efficiency, Fig. 3, begins to decrease when the majority of particles within the range used overcome $\operatorname{Re}_{7}$ (at $800{ }^{\circ} \mathrm{C} 45$ bar particles $>35 \mu \mathrm{m}$ ) because the bigger particles may splash or bounce-off at impact. Nevertheless, generalized splashing and fracture are only shown in the coating when most of the particles impact at a $R e$ above $R e_{7}$. Consequently, the 

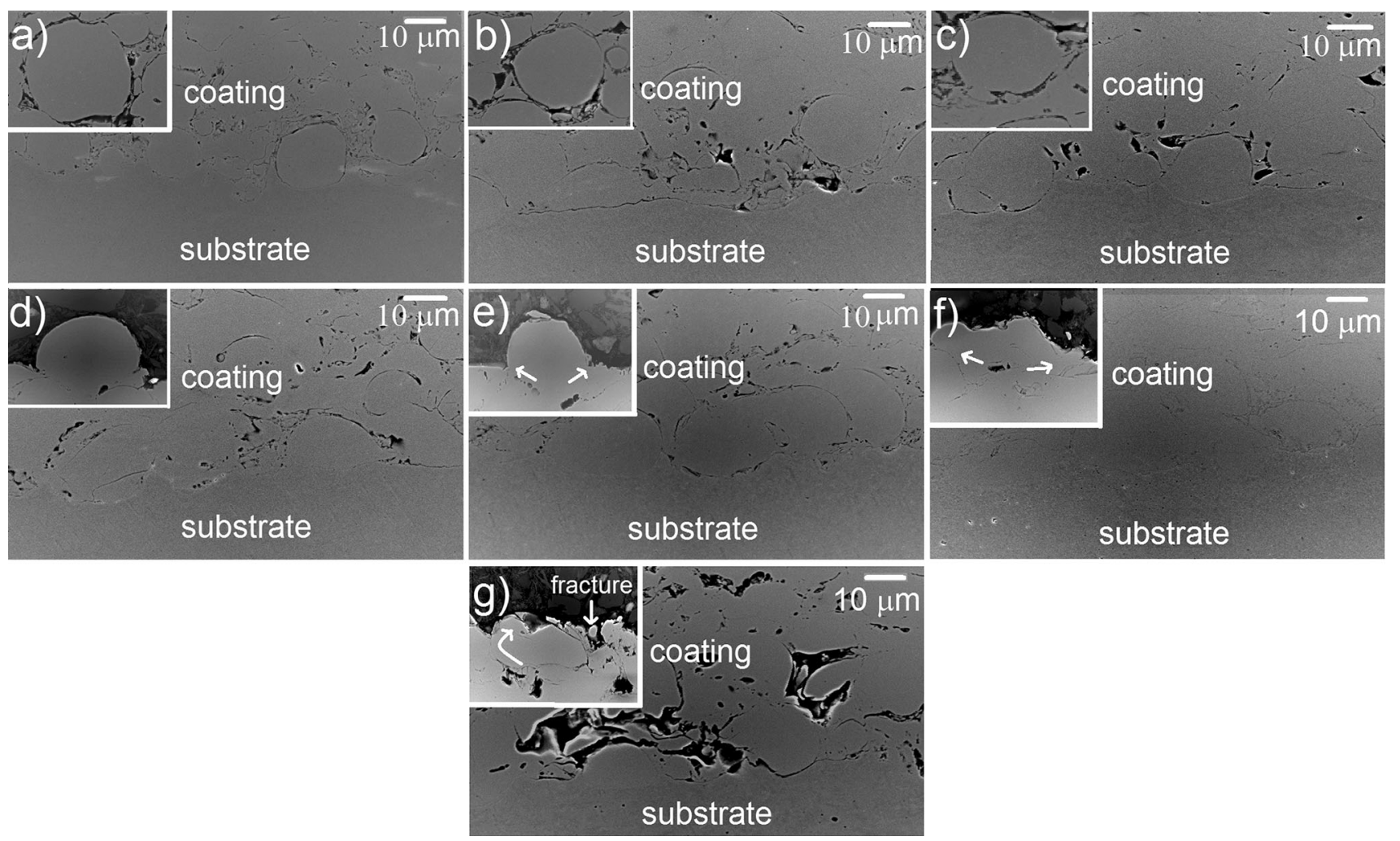

Fig. 4 Cross section of the Fe-base metallic glass coatings deposited onto 1040-steel using the spraying conditions of Table 3 for: (a) $R e_{1}$, (b) $R e_{2}$, (c) $R e_{3}$, (d) $R e_{4}$, (e) $R e_{5}$, (f) $R e_{6}$ and (g) $R e_{7}$. The inset in the figure shows a high magnification view of the particles in the coating

deposition decreases and is independent of the impact surface. On the other hand, $R e_{\text {crit }}$ is affected by the interaction particle/substrate because the transition from inhomogeneous flow to homogeneous flow depends on the substrate used, as mentioned above. Therefore, the contribution of different particle sizes to coating build-up also depends on the substrate used. Further details about substrate/particle interaction will be discussed in section 4.2 and 4.3. In any case, the above description shows that the $R e$ of metallic glass particles at impact change similarly in the range of particle used. Therefore, a narrow distribution of particles is preferred to perform a good control of the process based on the Re since this ensures that most of the particles are impacting under similar conditions.

Thus, it can be concluded that conditions for obtaining metallic glass coatings are associated to those promoting viscous flow without excessive softening at impact. The $R e$ is useful to control the range of conditions in which metallic glass coatings can be obtained. As in the case of crystalline materials, a narrow particle size distribution ensures that most of the metallic glass particles soften simultaneously. In this way, metallic glass particles over a $R e_{\text {crit }}$ can easily flow after impact promoting metallic glass coating formation. The experiments carried out in this work show a $R e_{\max } \sim \mathrm{Re}_{7}$ that leads to excessive softening. It is worth mentioning that it cannot be taken as a general value since jet formation and splashing are phenomena depending not only in the $R e$ but also on the impact velocity. Finally, it is worth mentioning that $R e_{\text {crit }}$ is affected by the properties of the substrate material leading to different deposition efficiencies and different metallic glass coating microstructures.

\subsection{Particle Viscoplastic Deformation Dependence on the Mechanical Properties of the Substrate Material}

The Re corresponding to the different impact conditions expresses the state of the particle prior to impact, but as seen in the results section, the final deformation state also depends on the substrate material. Figure 8(a) shows the aspect ratio of the particles, in contact to the substrate, in function of the $R e$. In all cases, the deformation improves increasing $R e$, which is represented by the decrease of aspect ratio. The increment of $R e$ is associated to the softening of the particles at impact, and therefore they can flow easily at impact, and achieve higher degree of deformation. This result has also been observed in previous studies (Ref 26, 28, 29, 47, 48, 50) spraying metallic glass particles onto steel substrate, the improved deformation led to better deposition efficiency. In addition to the above discussed, the present result also shows that the harder the substrate material, for instance Inconel 625 (open squares in Fig. 8a), the smaller the aspect ratio at the same $R e$, i.e., different degrees of particle deformation at the same initial impact conditions. However, if one compares 1040-steel and Aluminum-7075-T6 alloys, which 

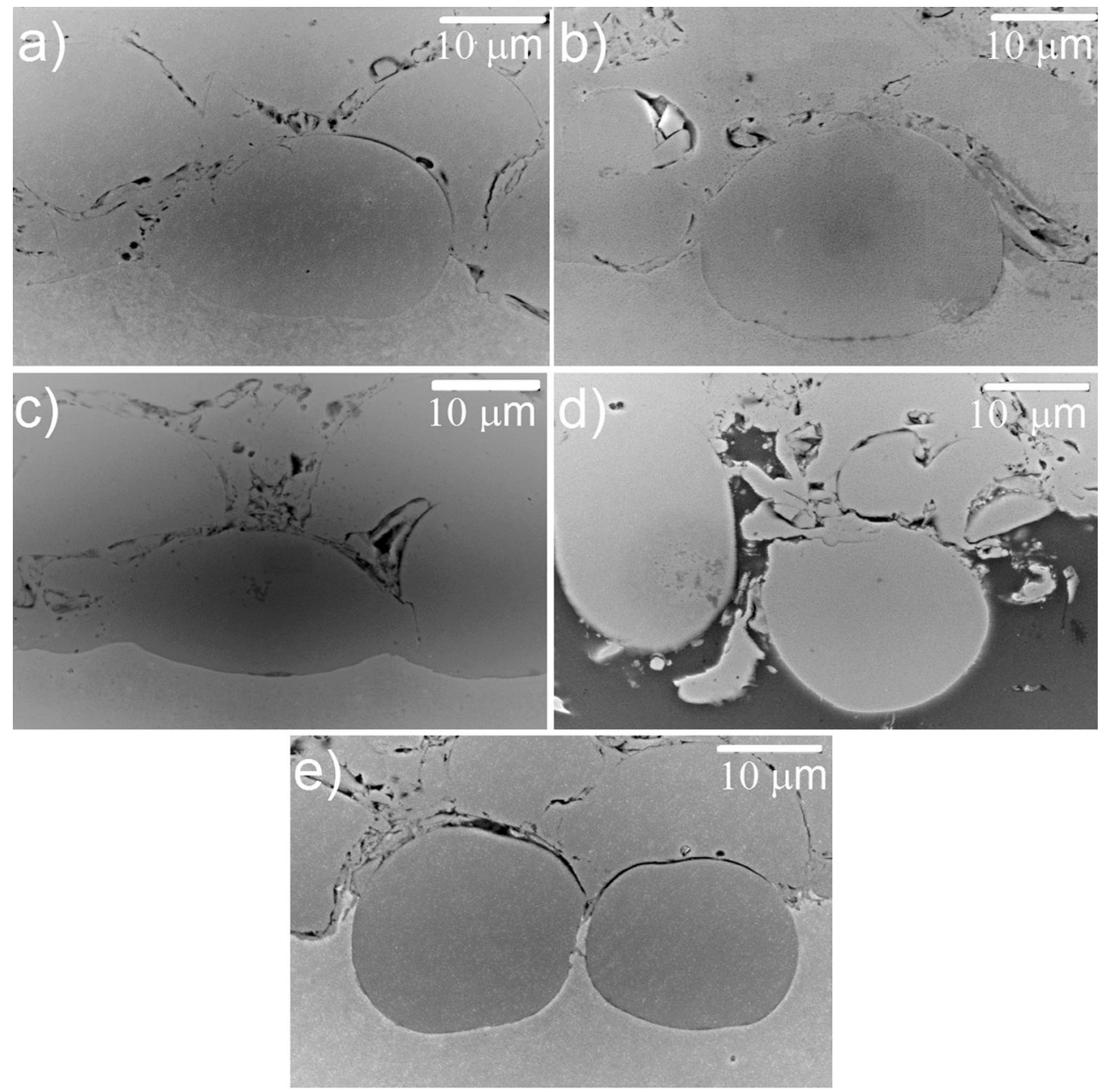

Fig. 5 Impact morphology of the Fe-base metallic glass particles onto: (a) 1040-steel, (b) 316L-steel, (c) Inconel-625, (d) Aluminum7075-T6, and (e) Copper $(99.9 \%)$ at $R_{5}(=1.2), 800{ }^{\circ} \mathrm{C}, 40$ bar, $10 \mathrm{~mm}$

are materials with a similar hardness, 178 and $155 \mathrm{Hv}$, respectively, it would be expected a very similar aspect ratio distribution. However, according to Fig. 5, Aluminum-7075-T6 alloy presents very low resistance to penetration compared to 1040-steel, i.e., metallic glass particles are embedded into the Aluminum-7075-T6 substrate, while particles deform more and penetrate less in the 1040-steel. This difference rises from the strain hardening and strength coefficient of Aluminum-7075-T6 with respect to the 1040-steel substrate under compression, since both parameters determine the flow stress behavior of metals. Under compression, Aluminum-7075 presents a lower strain hardening and strength coefficient (i.e., easier dislocation cross slip) and the substrate flows easily under the application of similar stresses in comparison to the steel substrate (Ref 51, 52). Moreover, SEM images, Fig. 5, show very different characteristics of particle deformation upon impact, which also suggests a very important effect of the particle/substrate thermal interaction, as discussed in section 4.3.

With the aim of studying in more detail the particle/substrate mechanical interaction at impact, a simple model based on the experimental penetration depth $\left(\delta_{\text {exp }}\right)$ and the aspect ratio of the metallic glass particles has been developed to estimate the viscous work spent during impact to deform the metallic glass particles. According to the law of conservation of energy, an energy balance between the kinetic, the viscous dissipation and the surface energy has been conducted (Ref 21, 53):

$$
\begin{aligned}
& E_{\mathrm{Ko}}+E_{\mathrm{so}}=E_{\mathrm{sf}}+W_{\text {substrate }}+E_{\mathrm{R}}+W_{\text {viscous }} ; \\
& E_{\mathrm{eff}}+E_{\mathrm{so}}=E_{\mathrm{sf}}+W_{\text {viscous }}
\end{aligned}
$$

where $E_{\mathrm{Ko}}$ represents the kinetic energy calculated from the impact velocity and the mean particle size of the metallic glass particles at the different conditions in this work $\left[E_{\mathrm{Ko}}=1 / 2 m v_{\mathrm{o}}^{2}\right.$ ) see impact velocity in Table 3. $E_{\mathrm{so}}$ is defined as the surface energy of the particle before impact $\left(E_{\mathrm{so}}=\pi D^{2} \sigma\right.$; where $\sigma$ is the surface tension for the $\mathrm{Fe}$ base metallic glass (Ref 54)). $E_{\text {sf }}$ corresponds to the surface energy after impact at its maximum splat diameter $D_{\max }\left(E_{\mathrm{sf}}=\pi / 4 \times D^{2} \sigma\left(1-\operatorname{Cos} \theta_{a}\right)\right)$ for $\theta_{a}=90^{\circ}(\operatorname{Ref} 53)$. $W_{\text {substrate }}$ is defined as the energy dissipated by the frictional and the plastic work during the substrate deforma- 


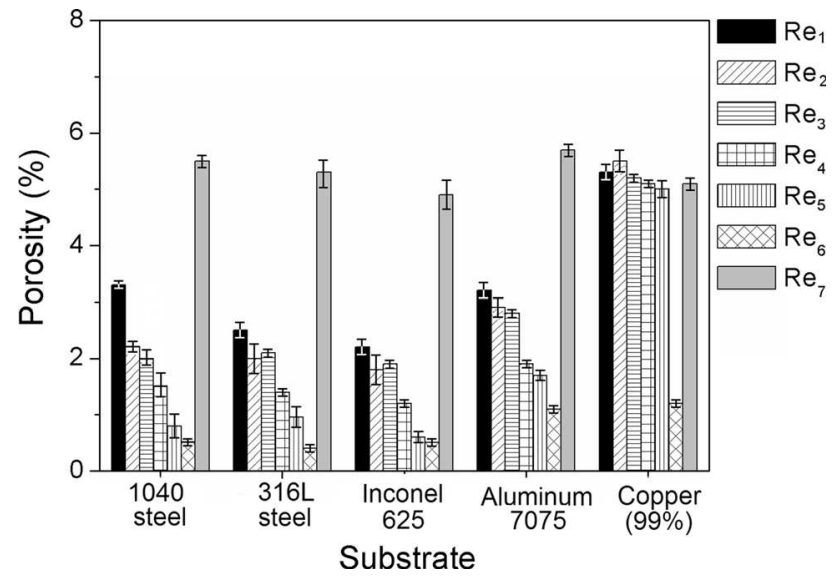

Fig. 6 Porosity of the Fe-base metallic glass coatings according to the substrate used and the $R e$

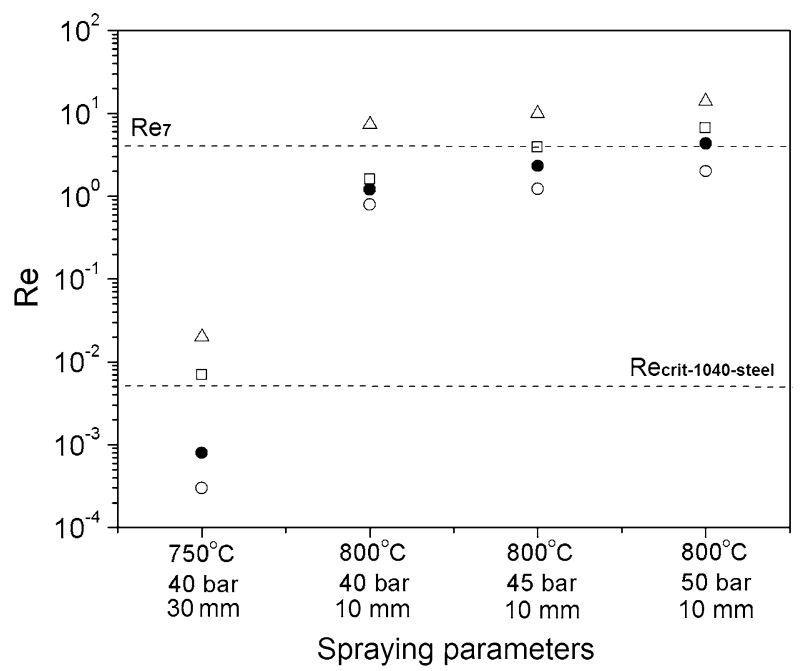

Fig. 7 Re number for different particle sizes: ( $(: 25$ microns; $\bullet: 30$ microns; $\square: 35$ microns; $\triangle: 40$ microns) as a function of the temperature and pressure of the carrier gas, and the stand-off distance. The dashed line at bottom represents the $R e_{\text {crit }}$ measured experimentally on 1040-steel, while the dashed line at the top shows $R e_{7}$

tion and $E_{\mathrm{R}}$ is the recoverable strain energy by both the substrate and the particle. $W_{\text {viscous }}$ represents the energy available to deform the metallic glass particle in the supercooled liquid state upon impact. For simplicity, the term $E_{\text {eff }}$, namely effective kinetic energy, was introduced in $\mathrm{Eq}$ 3. $E_{\text {eff }}$ is defined as the difference between $E_{\mathrm{Ko}}$ and $W_{\text {substrate }}$.

In order to evaluate the plastic work carried out on a substrate by a hard particle impacting its surface,

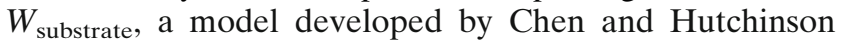
(Ref 55) has been used. Their work was based on metallic particles impacting metallic substrates at high velocity $(300-400 \mathrm{~m} / \mathrm{s})$ and high strain rates $\left(10^{4} \mathrm{~s}^{-1}\right)$. These are very similar conditions compared to the CGS process. They used finite element analysis to determine the residual stresses and geometric stress concentration on the substrate material. The most important non-dimensional parameters governing impact indents were identified, significantly reducing the set of material independent parameters. In (Ref 55), the parameter $\Omega$ is defined as the kinetic energy of the impacting particle $\left(E_{\mathrm{K}}\right)$ normalized by the yield stress of the substrate material $\left(\sigma_{\mathrm{y}}\right)$ given in Table 2.

$\Omega=\frac{E_{\mathrm{K}}}{\sigma_{\mathrm{y}} D^{3}}=\frac{\pi}{12}\left(\frac{\rho_{\mathrm{p}}}{\sigma_{\mathrm{y}}}\right) v^{2}$

Interestingly, Chen and Hutchinson found that the penetration depth of a particle into a substrate $(\delta)$ normalized by its initial diameter $(D)$ can be expressed in terms of $\Omega$ as long as the combination of deformation and density ratio between particle and substrate material are high enough (Ref 55):

$\frac{\delta}{D}=0.27 \sqrt{\Omega}(0.1+0.70 \sqrt{\Omega})$

Equation 4 includes the pile-up effect that typically appears in ductile materials and is independent of the elasticity of the substrate. In the present work, Eq 4 was solved introducing $D$, namely $30 \mu \mathrm{m}$, to find out the theoretical value of $\Omega\left(\Omega_{\text {theo }}\right)$ from Eq 3 for conditions corresponding from $R e_{1}$ to $R e_{5}$. The estimated value of $\delta$ for each $R e$ and substrate material was called the theoretical impact depth $\left(\delta_{\text {theo }}\right)$. In this sense, it was supposed that Eq 4 is valid only in the case that $\delta_{\exp } \leq \delta_{\text {theo }}$ since not all the kinetic energy is consumed at impact as plastic work on the substrate side. On the other hand, Eq 4 was also solved using $\delta_{\exp }$ in order to find out the experimental values of $\Omega\left(\Omega_{\exp }\right)$. The ratio $\Omega_{\exp } / \Omega_{\text {theo }}$ versus the ratio $\delta_{\text {exp }} / \delta_{\text {theo }}$ has been plotted in Fig. 8(b). Most of the conditions studied in this work fulfill the condition $\delta_{\exp } \leq$ $\delta_{\text {theo, }}$ i.e., points to the left of the vertical dashed line in Fig. 8(b). Two conditions corresponding to $R e_{5}$ in metallic glass coatings deposited onto Aluminum-7075-T6 and Copper $(99.9 \%)$ present a $\delta_{\exp }>\delta_{\text {theo }}$ due to a larger experimental impact depth, i.e., points to the right of the vertical dashed line in Fig. 8(b). Interestingly, $\Omega_{\exp }$ $\Omega_{\text {theo }}<1$ suggests that part of the initial kinetic energy has been spent in viscoplastic deformation of the metallic glass particle.

In order to solve $\mathrm{Eq} 2, \Omega_{\exp }$ values have been introduced in Eq 3 and $E_{\text {eff }}$ calculated using $E_{\mathrm{k}}=E_{\text {eff. }}$. For the two experiments with $\delta_{\text {exp }}>\delta_{\text {theo, }}, E_{\text {eff }}$ has been calculated assuming that a $95 \%$ of the initial kinetic energy was spent as plastic work. This assumption has been taken considering the almost unaffected particle spherical shape upon impact.

Figure 8(c) shows $W_{\text {viscous }}$ in function of the experimental aspect ratio of the metallic glass particles onto the different metallic substrates for conditions from $R e_{1}$ to $R e_{5}$. One can note that harder substrates lead to larger $W_{\text {viscous. }}$ For instance, Inconel 625 has values of $W_{\text {viscous }}$ around $20 \times 10^{-6} \mathrm{~J}$, while $W_{\text {viscous }}$ is close to 0 for metallic glass particles impacting onto Copper (99.9\%). Interestingly, in Fig. 8(c), the aspect ratio is smaller as the $W_{\text {viscous }}$ takes larger values describing a linear behavior in each 


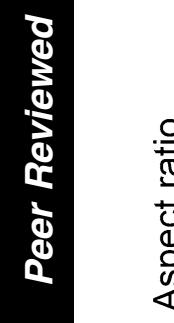
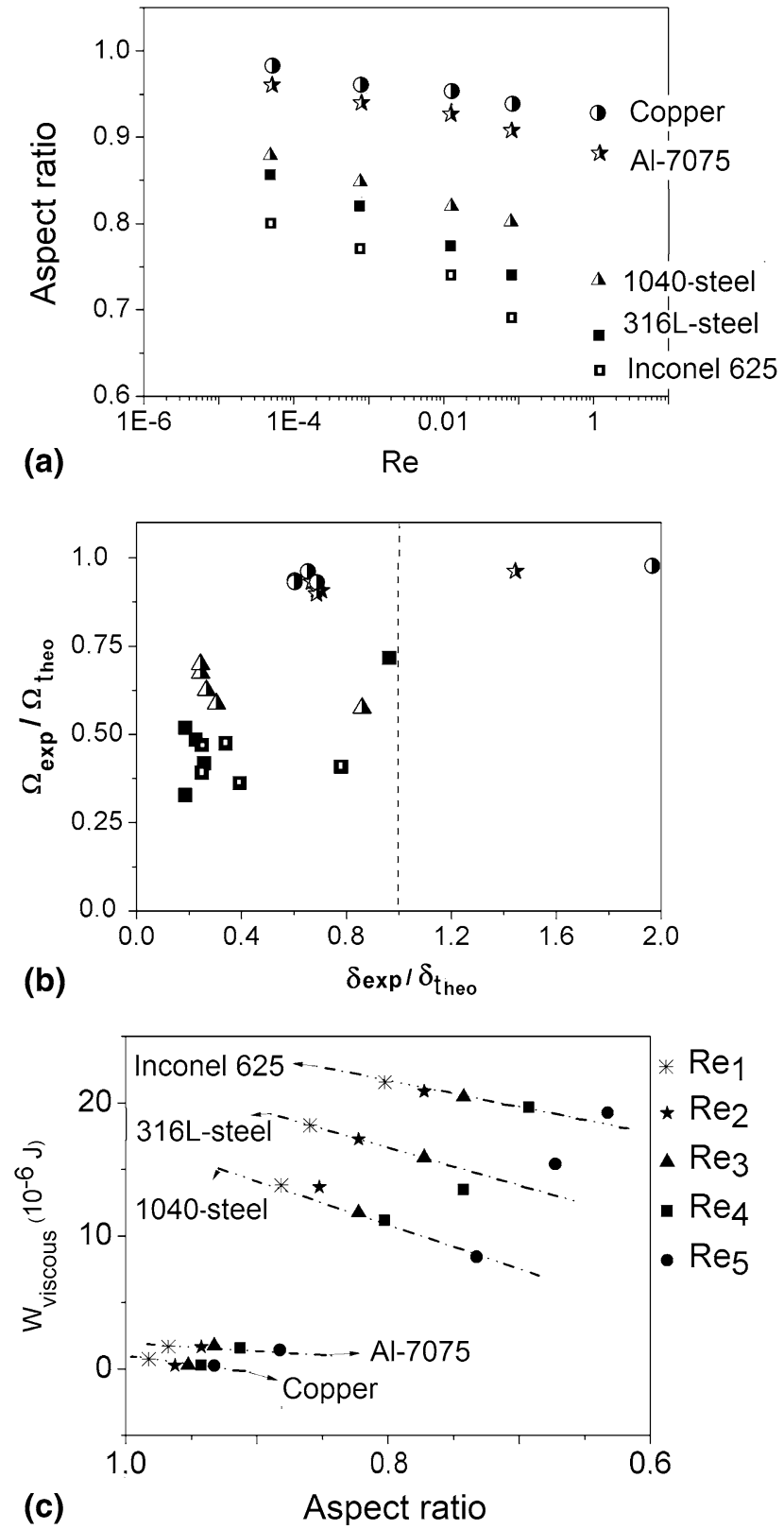

Fig. 8 (a) Aspect ratio (dimensionless) vs. Re; (b) Ratio of dimensionless impact energy vs. ratio of penetration depth, and (c) viscous energy vs. aspect ratio

single $R e$, for example at $R e_{5}$, the aspect ratio is 0.63 at high $W_{\text {viscous }}$ values and 0.93 at small $W_{\text {viscous }}$ values. Previous studies using crystalline metals deposited by CGS suggest that the energy dissipated in plastic deformation is mostly spent in the softer part of impact (Ref 21, $31,36)$, just as happened in this work using a metallic glass. Therefore, Fig. 8(c) reveals quite different viscous dissipation energies, and different deformation behaviors in the case of metallic glass particles depending on the mechanical properties of the substrate, which is in agreement with the dissimilar aspect ratio observed in Fig. 8(a). This suggests that a substrate with a large hardness pro- motes extremely high strain rates, similar to crystalline materials (Ref 21, 31), and therefore the energy spent in viscous dissipation is larger than in softer substrates.

According to the definition of viscous work (Ref 56), the viscous work is expressed in terms of the metallic glass viscosity $(\eta)$, the shear strain rate $(\dot{\gamma})$ and the finite strain $(\varepsilon)$, see Eq 5. In 2-dimensions, the $\varepsilon$ can be expressed in terms of the aspect ratio (AR) giving a measure of the overall intensity of distortion of a circle of area $(A)$, which represents the metallic glass particle of mass $(m)$ and density ( $\rho)$, becoming an ellipse upon impact (Ref 57).

$$
\begin{aligned}
d\left(W_{\text {viscous }}\right) & =(\tau \cdot d A) \cdot v=\text { shear stress times impact velocity } \\
W_{\text {viscous }} & =\int\left(\eta \cdot \dot{\gamma}^{2} \cdot \varepsilon \cdot \frac{m}{\rho}\right) \mathrm{d} A \\
W_{\text {viscous }} & =\left(\eta \cdot \dot{\gamma}^{2}\right) \cdot \frac{m}{\rho} \cdot A \cdot(1-A R)
\end{aligned}
$$

Equation 5 describes qualitatively the experimental behavior of the metallic glass particles shown in Fig. 8(c). The variation of the slope for the same $R e$ and different substrates in Fig. 8(c) is related to the viscosity and the shear strain rate undergone by the metallic glass particles. For the same initial $R e$, i.e., same viscosity and velocity, a larger shear strain rate is achieved with increasing substrate hardness leading to higher $W_{\text {viscous }}$ and lower aspect ratio. When $R e$ is small, for instance $R e_{1}$, the viscosity becomes too large and strain rates extreme. Under this condition, the slope increases and the energy spent to reach certain degree of distortion becomes large. At larger $R e$, i.e., $R e_{5}$, the viscosity decreases various orders of magnitude, and therefore the viscous energy necessary to deform the MG particle for a given aspect ratio is smaller.

In overall, the results of this section show that metallic glass particles impacting at any $R e$ onto soft metallic substrates present almost no deformation after impact. This behavior is very similar in crystalline particles impacting onto softer substrates (Ref 21, 25, 31, 36). In both cases, the plastic deformation is concentrated in the soft substrate leading to excessive plastic flow of the substrate and embedment of the particle. Increased substrate hardness allows the activation of viscous flow in the metallic glass particles and plastic deformation is possible at the different studied Re, Fig. 3 and 8. A similar result is reported for crystalline materials, where particles impacting onto hard substrates show higher deformation (Ref 21, 25, 35). However, the deformation mechanisms leading to this result are completely different depending on the nature of the sprayed particles. Particles of crystalline materials impacting hard substrates experience softening due to the higher induced shear strain rates and temperatures that allow easier dislocation movement, i.e., easier plastic deformation. According to Fig. 8 and Eq 5, metallic glass particles impacting onto hard substrates also deform more extensively due to the induced higher shear strain rates and temperature at the particles but in this case, the higher softening is due to the shear-thinning experienced by the undercooled liquid. On the other hand, if the substrate is sufficiently hard, the rebound energy 
developed by the metallic glass particle is sufficiently high to bounce back at impact, especially in the case of stiffer materials. The energy of the process associated to the particle rebounding, namely the rebound energy $\left(E_{\mathrm{R}}\right)$, is defined in function of the elastic properties of the substrate material and the velocity of the particle at impact (Ref 46). For example, in this work, the impact velocity and temperature of the particle have been exactly the same independently on the substrate used, Table 3; therefore the difference of behavior exclusively comes from the substrates properties. Interestingly, the deposition efficiency onto the hardest substrate, Inconel-625, is rather low despite the large particle deformation, large $W_{\text {viscous }}$ and large $E_{\text {eff }}$, in contradiction to the high deposition efficiency obtained onto 1040-steel and 316L-steel with lower $W_{\text {viscous }}$. The high elastic limit, i.e., high hardness, and high elastic modulus of Inconel-625, see Table 2, makes $E_{\mathrm{R}}$ large in this case, leading to a higher probability of particle rebounding onto this substrate and therefore a lower deposition efficiency, as observed in the present work.

\subsection{Effect of the Thermal Properties of the Substrate}

Typically, bonding in CGS metallic coatings is studied under the assumption of an adiabatic process (Ref 12, 20). This assumption is in many cases true due to the fact that the rate of heat dissipation in the distances associated to the process does not affect the conditions of the plastic deformation. However, it has been demonstrated that under some particular situations, such as particle thermal activation, the thermal interaction substrate/particle becomes crucial changing the distribution of temperature in the contact area and all over the particle $(\operatorname{Ref} 21,33)$. This type of differences between the adiabatic and thermal analysis becomes really important when the materials involved are very sensitive to temperature, where any variation in temperature might represent the change of deformation behavior and/or phase transformations. At least for metallic glasses, an adiabatic study cannot support and explain all the results related to the process and it becomes crucial considering the heat transfer due to the viscous nature and its exponential dependence on temperature. Upon this point, calculations have been carried out taking into account the metallic glass particle/substrate thermal conduction in the early stages of impact.

In CGS, when particles are propelled and impact onto the surface of a substrate, there is a time in the range of $1 \times 10^{-8}$ to $5 \times 10^{-8} \mathrm{~s}$ in which particle deformation does not take place (Ref 20). During this time of impact, an elastic collision takes place, and it is followed by an elastic unloading whereas the shape of the particle is partially recovered. In this range of time, a temporal change in temperature in the particle/substrate contact area is given, and it could be different depending on the thermal properties of the substrate material. The temperature change might go on as soon as the particle deformation occurs and the contact surface becomes larger. Although the heat transfer in the case of a metallic glass particle impacting on a substrate is a dynamic process, the temporal change in temperature in the early stages could be considered as the precursor of very different subsequent metallic glass deformation modes and substrate plastic deformation. It is worth mentioning that the Fe-base metallic glass used in this investigation is characterized to be a fragile liquid (Ref 28). This means that the viscosity of the metallic glass particle could change from the order of $10^{2}$ to $10^{12} \mathrm{~Pa} \mathrm{~s}$ with just a change in temperature of $50{ }^{\circ} \mathrm{C}$. A rapid heat extraction from the particle due to a high thermal diffusion coefficient of the substrate material could lead to a completely different deformation behavior, i.e., as a brittle solid instead of a liquid. Calculations were carried out for single impact of a metallic glass particle for times in the order of $10^{-8} \mathrm{~s}$ and for the different metallic substrates studied in this work. It was assumed, based on previous investigations (Ref 31,33), particle/substrate perfect contact. This assumption is supported by the fact that CGS particles impact occurs at very high velocity developing very high contact pressures.

Figure 9(a) shows the viscosity change due to temperature evolution in function of the radius of a metallic glass particle after $10^{-8} \mathrm{~s}$ of the impact onto the different substrates studied in this work for $R e_{5}$ conditions. The viscosity from the surface until $250 \mathrm{~nm}$ inside the metallic glass particle increases from the initial viscosity of $10^{2}$ up to $10^{12} \mathrm{~Pa}$ s when the impact takes place onto Copper and Aluminum-7075-T6. Furthermore, the viscosity is still as high as $10^{5}-10^{6} \mathrm{~Pa} \cdot \mathrm{s}$ at $350 \mathrm{~nm}$ in these two substrates. This big increase in viscosity means that the impact surface changes from a supercooled liquid to a brittle and extremely hard solid, i.e., a metallic glass. Further particle deformation is hindered due to this hard surface layer in the case of high heat conductivity substrates. On the other hand, substrate materials with much lower heat conductivity present a much more moderate increase of viscosity at $250 \mathrm{~nm}$ from the particle surface and at $350 \mathrm{~nm}$ the viscosity is lower than $10^{4} \mathrm{~Pa}$ s for the 1040-steel, 316Lsteel and Inconel-625 allowing the deformation of the particle.

According to the present calculations, in agreement with the experimental results, it is clear that differences in particle deformation and penetration rise not only from the mechanical properties of the substrate, but also from its thermal properties. The largest heat transfer rate at the substrate impact surface of Copper and $\mathrm{Al}$ alloys has been already proved in previous works using crystalline particles (Ref 32). In the present case, when a metallic glass particle is sprayed onto materials with high thermal conductivity such as Copper (99.9\%) and Aluminum-7075-T6, the metallic glass particle itself has almost no deformation due to the high heat flux from the particle to the material which leads to a high increase of viscosity at the metallic glass particle surface. This hard surface allows the particle to penetrate much more into the substrate. Thus, compared to 1040-steel, 316L-steel and Inconel-625 substrates, the metallic glass particle penetrates more deeply and it presents almost no deformation on Copper (99.9\%) and Aluminum-7075-T6. Of course, at the beginning of the plastic deformation factors as frictional heating and the 
strain rate effect on the viscosity could deplete the increase of the viscosity. However, the strain rate and heating are often localized and the fact of increasing the particle/substrate contact area could result in a monotonical increase in viscosity (when the substrate possesses a high thermal diffusivity) even after the initial impact stage. Previous works using crystalline materials sprayed by cold gas showed similarly improved deposition when substrate presents low heat extraction (Ref 32, 38, 58). Nevertheless, unlike crystalline materials, metallic glass particles are more sensitive to thermal properties of the substrate because viscosity depends exponentially on temperature.

The influence of the thermal properties of the substrate materials on the particles deposition has also been taken into account. The formation of the metallic glass coatings consists in simultaneous and successive impacts onto a substrate. Once a first set of particles impact the substrate, another set of particles are deposited onto the first ones and the thermal field can be rapidly perturbed in the impact location. Figure 9(b) shows the experimental deposition efficiency versus the thermal diffusivity of the substrate materials after one and three passes of the spraying gun. Interestingly, the deposition efficiency in the high thermal diffusive materials decreases between the first and the third pass. This suggests that the substrate/coating temperature during the first pass of the spraying gun and during the second pass and third pass can be really different depending on the thermal properties of the substrate. In this case, if the first layer is cooled by a particular substrate material faster than another, the characteristics of particle deformation in the subsequent layers will definitely be affected. The substrates with higher thermal diffusivity, i.e., Copper (99.9\%) and Aluminum-7075-T6, cool the first metallic glass layer more quickly than the rest of the substrates. Therefore, the metallic glass particles forming the second and third layer impact onto a cooler and very hard metallic glass surface promoting high strain rates, high rebounding energies and higher surface viscosity. In these conditions, a decrease in deposition efficiency should be expected in agreement to the results displayed in Fig. 9(b).

\subsection{Mechanisms of Metallic Glass Particle Deposition}

The deposition of metallic glass particles onto very different substrates has revealed the mechanisms of metallic glass particle deformation and the necessary conditions for metallic glass coating build-up. In this section, the similarities and differences between the mechanisms of particle deposition of a crystalline material and a metallic glass are discussed and clearly illustrated.

A metallic glass particle deformed in the homogeneous flow regime onto 1040-steel is observed in Fig. 10(a) for the experimental conditions of $R e_{3}$ in this work. Note that intimate contact is promoted upon impact of the metallic glass particle. A clear limit between the substrate and the metallic glass particle is difficult to observe. The substrate is severely deformed due to the high stress level experi-
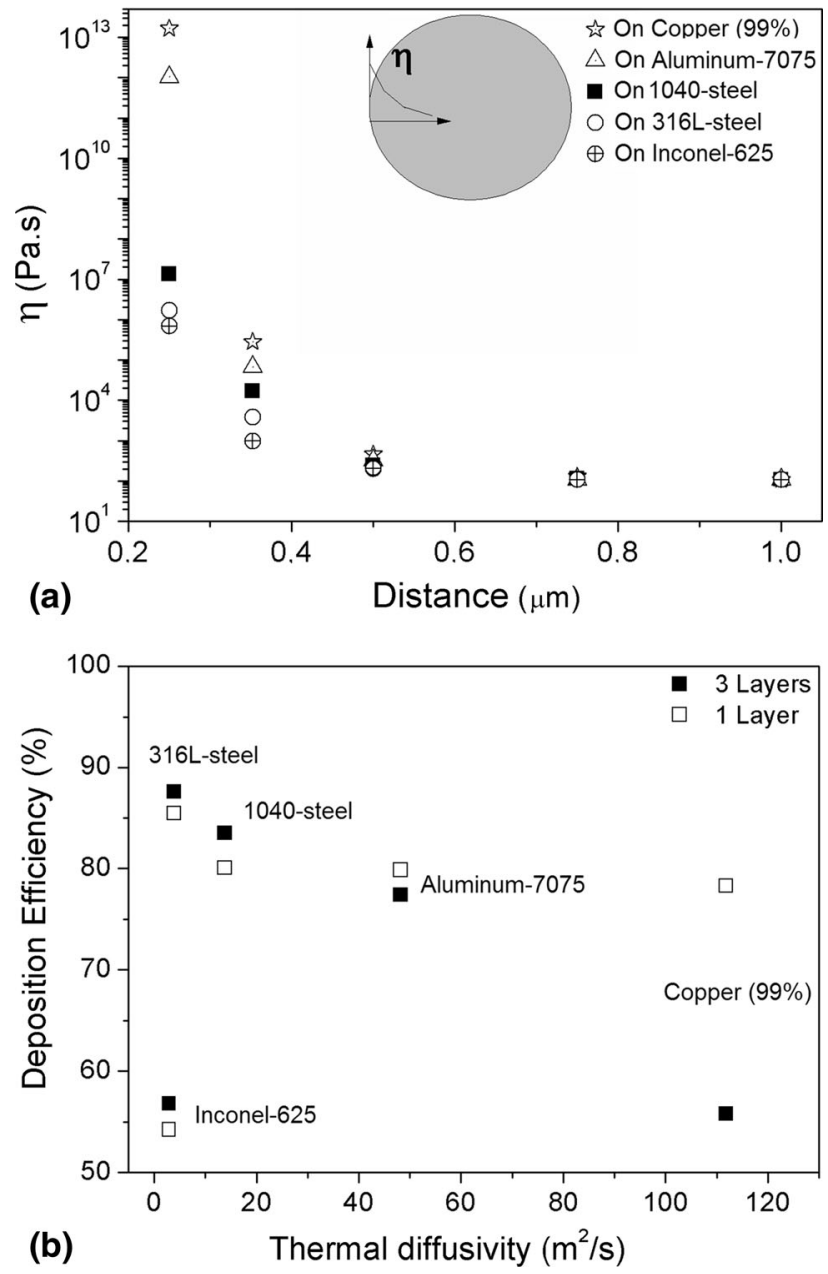

Fig. 9 (a) Gradient of viscosity in the surface of a Fe-base metallic glass particle during the temporal impact in a time in the order of $1 \times 10^{-8} \mathrm{~s}$ obtained by finite element simulation. (b) Experimental deposition efficiency for 1 layer and 3 layers of Febase metallic glass coatings versus the thermal diffusivity of the different substrates

enced at impact and as consequence a jet is formed. In Fig. 10(b), a higher magnification view of the metallic glass particle in homogeneous regime after etching for 5 min with Nital is presented. Note the area limited by the dashed lines, where the metallic glass seems to have experienced extreme viscous flow and a structure like a liquid. As mentioned previously, non-Newtonian regime is promoted in metallic glasses deforming in homogenous flow, depending on the combination of strain rate and temperature. Considering the high strain rates concentrated in the impact zone, Fig. 10(b) suggests that metallic glass particles impacting under this condition show nonNewtonian behavior around the surface of impact. This is typically seen in viscous liquids with shear thinning phenomena, and it has been already reported in metallic glasses in the supercooled liquid state (Ref 59). Under such conditions, the metallic glass viscosity drops exponentially and the liquid can flow easily. In the case of a metallic glass particle in the CGS process deforming in 

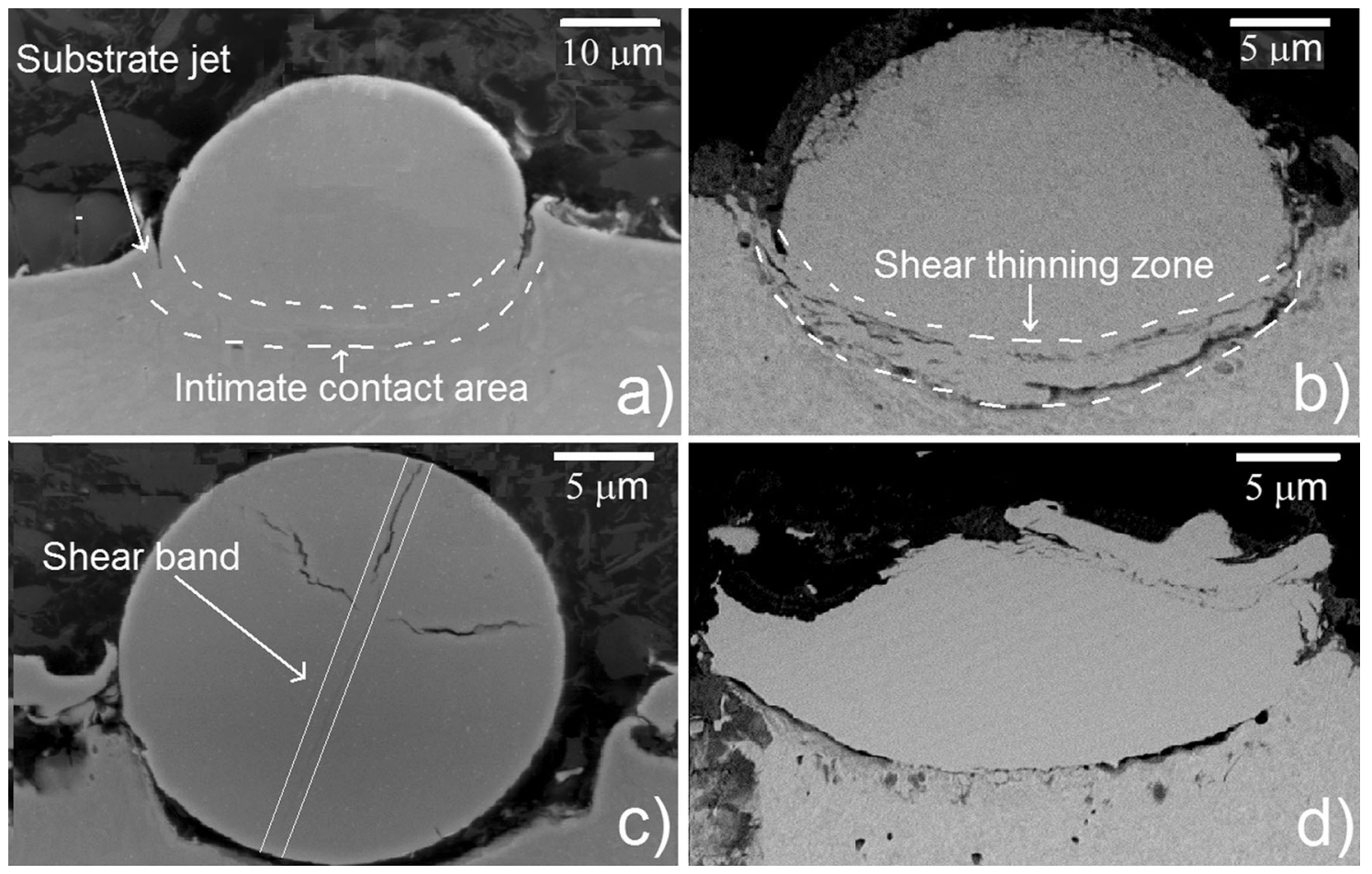

Fig. 10 Different deformation states for the Fe-base metallic glass particles onto 1040-steel substrate at: (a) $R e_{5}$, (b) $R e_{5}$ etched with Nital for 5 min, (c) $R e_{1}$ and (d) $R e_{7}$

homogenous flow, Fig. 10(b), the shear thinning phenomena are given due to the stress localization at the surface of impact, promoting an increase in the viscoplastic deformation, an intimate particle/substrate contact, and high deposition efficiency as mentioned previously. If this condition is not fulfilled, it could give rise to two possible situations: one case associated to very small $R e$, and another associated to very large Re. Figure 10(c) shows a metallic glass particle sprayed at conditions of $R e_{1}$ (a small $R e$ number in this work). Under this condition, metallic glass particle deforms inhomogenously promoting shear bands and cracks. Since the deformation is localized through the shear bands, then the impact surface is not able to flow, and therefore bonding is not achieved. Figure 10(d) shows a particle sprayed at conditions of a large $\operatorname{Re}\left(\operatorname{Re}_{7}\right)$. Under this condition, the metallic glass particle deforms in the homogenous flow regime and presents excessive shear thinning, i.e., low viscosities, leading to the formation of jets at the edge of the particle. This type of deformation is also suitable for a good bonding because a large substrate/particle contact area is promoted. However, as mentioned previously, the particle/particle impact under conditions of a very large $R e$ leads to fracture of the metallic glass particles. Thus, coating growth is affected and highly porous coatings obtained, as shown in Fig. 6.

In this manner, according to Fig. 10 and following the discussed above, good particle bonding and high deposition efficiency are promoted under homogeneous defor- mation around the surface of impact for metallic glasses impacting in the supercooled liquid state. When these conditions are not satisfied, either by a poor or excessive softening of the metallic glass particle, the characteristics of the impact and coating formation are changed, leading to poor deposition efficiency and a porous microstructure as a result of particle rebounding or particle fracture.

A description of the deposition mechanisms of metallic glasses by CGS is presented in Fig. 11 as a flow chart concerning both a crystalline metal and a metallic glass. Although the conditions promoting metallic glass deposition have shown similarities with the conditions needed to obtain bonding of crystalline metals, the mechanisms involved in the deformation process and deposition for metallic glasses have a different physical explanation once compared with those already known for crystalline metals. In a crystalline metal, the bonding is given when the particle, overcoming a critical velocity, impacts onto the substrate and it experiences highly localized plastic deformation. In crystalline metals, plasticity is mainly governed by the movement of dislocations. For example, the breeding and interaction of dislocations is responsible for the work hardening. During the particle impact and due to the high strain rates experienced by the particles, the stress flow varies monotonically with the plastic strain while subsequent dislocation movements are occurring. The plastic strain energy is dissipated as heat and it promotes softening of the material. The thermal softening can lead to processes of dynamic recovery, 

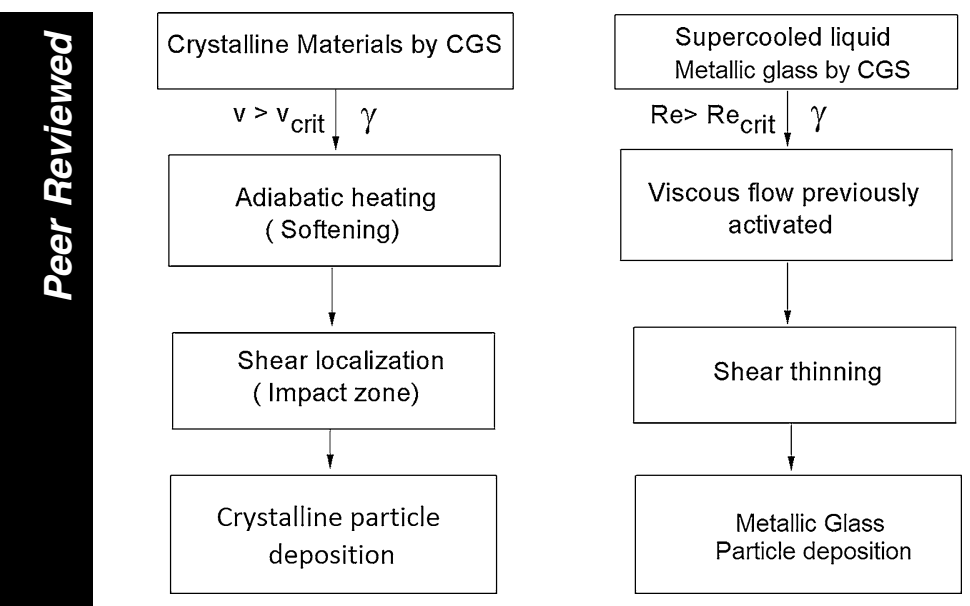

Fig. 11 Flow chart of the deposition mechanisms for a crystalline metal and a metallic glass

recrystallization, and even shear banding (Ref 31, 60). The type of process following the thermal softening is exclusively a function of the properties of the particle material and its interaction with the substrate. Typically, shear bands can appear in the impact surface of the crystalline metallic particle in materials with a low thermal conductivity. In any case, the plastic flow becomes localized at the particle/substrate impact surface as a consequence of the thermal softening and stress concentration. This means that the thermal softening dominates over the work hardening upon impact. The shear localization causes the flow of interfacial region consisting in a highly deformed material; it promotes intimate contact particle/substrate and therefore particle bonding (Ref 20, 21, 39).

On the other hand, a metallic glass presents two deformation modes: homogenous deformation and inhomogeneous deformation according to the deformation maps given by Spaepen (Ref 61). The present and our previous studies (Ref 28,29) demonstrate that deformation in conditions of homogenous flow is essential because it promotes viscous dissipation at the interfacial particle/substrate area and a high particle/substrate contact area. This means that the total energy involved in the CGS process must be high enough in order to activate viscous flow in the metallic glass particles at impact and subsequent shear-thinning. This condition can be easily achieved by controlling the $R e$ of the metallic glass particle. However, the thermo-mechanical properties of the substrate play an important role to activate viscous flow in the impacting particles. A hard substrate favors particle deformation and shear thinning because of the high strain rates experienced by the particles. At the same time, a very hard substrate also promotes large $E_{\mathrm{R}}$ and the number of rebounding particles becomes more important leading to a deposition efficiency decrease. In addition, a requirement for a good bonding is the substrate deformation. A very hard substrate will need higher impact energies in order to reach a good mechanical anchoring, as shown in Fig. 3 for Inconel-625. In this type of substrate, when viscous flow is thermally activated in the metallic glass particle (sufficiently large $R e$ ), deposition efficiency is still low compared to the coatings sprayed onto 1040steel or $316 \mathrm{~L}$-steel substrates since the $E_{\mathrm{R}}$ is still high enough, producing either a poor mechanical anchoring or a subsequent particle erosion in the particle/particle impact, or directly particle rebounding. On the other hand, substrates with high thermal diffusivity require metallic glass particles in conditions of a large $R e$ in order to keep the viscous flow activated during enough time to produce particle deformation, as suggested by Fig. 9. This is clearly shown in Fig. 3 for metallic glass coatings onto Copper (99.9\%) and Aluminum-7075-T6, which have a larger $R e_{\text {crit }}$ compared to the other substrates.

\section{Conclusions}

The effect of the substrate properties on the characteristics and deposition efficiency of the Fe-base metallic glass coatings produced by CGS were studied at different processing conditions. The experimental data were combined with different physical concepts related to the impact dynamic and the mechanics of deformation of metallic glasses in the supercooled liquid state. The comparison between calculations and experimental data have shown that mechanical and thermal properties of the substrate material have an important effect in the characteristics of the metallic glass particle deformation, in the bonding and in the microstructure of the metallic glass coatings by CGS. A summary of conclusions in this study is as follows:

1. The mechanical properties of the metallic substrate influence the strain rate conditions and the rebounding energy of the process. A hard substrate promotes high deformation rates and larger deformation of the particles, while soft substrates absorb most of the kinetic energy during impact leading to poor particle deformation. Therefore, hard substrates promote higher densification of metallic glass coatings. It is also worth mentioning that if the substrate is very hard and presents a large elastic limit, the rebound energy of the deformed particles can be sufficiently high to bounce back after impact, and the efficiency of the process could be deteriorated.

2. Thermal properties of the metallic substrate influence the rate of heat dissipation out of the metallic glass particle during impact, and thus it affects the deformation of the metallic glass. A high thermal diffusivity leads to a rapid surface cooling, and therefore metallic glass particles get temperatures below its glass transition point promoting inhomogeneous deformation. This finding proves that adiabatic analysis commonly used for crystalline metallic coatings should be avoided for metallic glasses.

3. It is confirmed that the deposition efficiency of metallic glass coatings build-up by CGS scales with the Reynolds number of the impacting particles. Interestingly, the analysis carried out gives further ele- 
ments with respect to the limits of the $R e$ for maximum deposition efficiency. Maximum deposition efficiency of metallic glass particles is expected just above $R e_{\text {crit }}$. In the present work, the $R e_{\text {crit }}$ was estimated for Fe-base metallic glass coatings sprayed onto 1040steel, 316L-steel, Inconel-625, Aluminum 7075-T6, and Copper (99.9\%), as 0.005, 0.007, 0.0131, 0.0356, and 0.054 , respectively. Spraying conditions leading to much larger $R e$ than $R e_{\text {crit }}$ can promote excessive metallic glass softening and a decrease in the deposition efficiency. On the other hand, low Re produces low deposition efficiency because deformation is localized into thin shear bands, generally leading to particle fracture and/or particle rebounding. Moreover, this study shows that a narrow range of particle sizes is needed to better control the impact conditions since $R e$ depends on particle size. In overall, the $R e$ remains a good criterion for describing the state of the metallic glass particles at impact and for predicting particle adhesion because it takes into account both the inertial and viscous forces acting on the particle.

4. This investigation demonstrates that the mechanisms involved in the metallic glass deposition are different to the mechanisms usually accepted for crystalline metals. Homogeneous flow and shear thinning are the main mechanisms of deformation involved in the deposition of metallic glass coatings. These mechanisms reflect the amorphous nature of metallic glasses and require thermal activation which is controlled by the $R e$. Interestingly, shear thinning is an essential step to achieve coating formation with high deposition efficiency.

\section{Acknowledgments}

The authors would like to thank IMPACT INNOVATIONS GmbH for their collaboration in coating deposition, EPSON-ATMIX for providing the powder used in this work, and the Generalitat de Catalunya through 2014 SGR 1558 for the financial support. The authors also acknowledge the CPT grant for supporting "John Henao" in his $\mathrm{PhD}$ program at the Universitat de Barcelona.

\section{References}

1. E. Axinte, Metallic Glasses from "Alchemy" to Pure Science: Present and Future of Design, Processing and Applications of Glassy Metals, Mater. Des., 2012, 35, p 518-556

2. J.Q. Wang, Y.H. Liu, M.W. Chen, G.Q. Xie, D.V. LouzguineLuzgin, A. Inoue, and J.H. Perepezko, Rapid Degradation of Azo Dye by Fe-Based Metallic Glass Powder, Adv. Funct. Mater., 2012, 22, p 2567-2570

3. A. Inoue, Stabilization of Metallic Supercooled Liquid and Bulk Amorphous Alloys, Acta Mater., 2000, 48(1), p 279-306

4. A.T. Patel and A. Pratap, Study of Kinetics of Glass Transition of Metallic Glasses, J. Therm. Anal. Calorim., 2012, 110(2), p $567-571$

5. G. Pookat, H. Thomas, S. Thomas, S.H. Al-Harthi, L. Raghavan, I. Al-Omari, and M.R. Anantharaman, Evolution of Structural and Magnetic Properties of Co-Fe Based Metallic
Glass Thin Films with Thermal Annealing, Surf. Coat. Technol., 2013, 236, p 246-251

6. W.H. Wang, C. Dong, and C.H. Shek, Bulk Metallic Glasses, Mater. Sci. Eng., 2004, 44(2), p 45-89

7. W.L. Johnson, Bulk Glass-Forming Metallic Alloys: Science and Technology, Mrs Bull., 1999, 24, p 42-56

8. A. Concustell, G. Alcala, S. Mato, T.G. Woodcock, A. Gebert, J. Eckert, and M.D. Baró, Effect of Relaxation and Primary Nanocrystallization on the Mechanical Properties of $\mathrm{Cu} 60 \mathrm{Zr} 22$ Ti 18 Bulk Metallic Glass, Intermetallics, 2005, 13(11), p 12141219

9. A.L. Greer, Y.Q. Cheng, and E. Ma, Shear Bands in Metallic Glasses, Mater. Sci. Eng., 2013, 74(4), p 71-132

10. D.B. Miracle, A. Concustell, Y. Zhang, A.R. Yavari, and A.L. Greer, Shear Bands in Metallic Glasses: Size Effects on Thermal Profiles, Acta Mater., 2011, 59(7), p 2831-2840

11. S. Ding, Y. Liu, Y. Li, Z. Liu, S. Sohn, F.J. Walker, and J. Schroers, Combinatorial Development of Bulk Metallic Glasses, Nat Mater., 2014, 13(5), p 494-500

12. T. Schmidt, H. Assadi, F. Gärtner, H. Richter, T. Stoltenhoff, H. Kreye, and T. Klassen, From Particle Acceleration to Impact and Bonding in Cold Spraying, J. Therm. Spray Technol., 2009, 18(5-6), p 794-808

13. W.Y. Li and C.J. Li, Optimal Design of a Novel Cold Spray Gun Nozzle at a Limited Space, J. Therm. Spray Technol., 2005, 14(3), p 391-396

14. W.Y. Li, H. Liao, G. Douchy, and C. Coddet, Optimal Design of a Cold Spray Nozzle by Numerical Analysis of Particle Velocity and Experimental Validation with 3161 Stainless Steel Powder, Mater. Des., 2007, 28(7), p 2129-2137

15. S. Grigoriev, A. Okunkova, A. Sova, P. Bertrand, and I. Smurov, Cold Spraying: From Process Fundamentals Towards Advanced Applications, Surf. Coat. Technol., 2005, 268, p 77-84

16. H. Tabbara, S. Gu, D. McCartney, T. Price, and P. Shipway, Study on Process Optimization of Cold Gas Spraying, J. Therm. Spray Technol., 2011, 20(3), p 608-620

17. T. Klassen, F. Gärtner, T. Schmidt, J.O. Kliemann, K. Onizawa, K.R. Donner, and H. Kreye, Basic Principles and Application Potentials of Cold Gas Spraying, Materialwissenschaft und Werkstofftechnik, 2010, 41(7), p 575-584

18. J. Villafuerte, Current and Future Applications of Cold Spray Technology, Metal Finish., 2010, 108(1), p 37-39

19. H. Assadi, T. Schmidt, H. Richter, J.O. Kliemann, K. Binder, F. Gärtner, and H. Kreye, On Parameter Selection in Cold Spraying, J. Therm. Spray Technol., 2011, 20(6), p 1161-1176

20. H. Assadi, F. Gärtner, T. Stoltenhoff, and H. Kreye, Bonding Mechanism in Cold Gas Spraying, Acta Mater., 2003, 51(15), p 4379-4394

21. G. Bae, Y. Xiong, S. Kumar, K. Kang, and C. Lee, General Aspects of Interface Bonding in Kinetic Sprayed Coatings, Acta Mater., 2008, 56(17), p 4858-4868

22. M. Chen, Mechanical Behavior of Metallic Glasses: Microscopic Understanding of Strength and Ductility, Annu. Rev. Mater. Res., 2008, 38, p 445-469

23. T.G. Nieh and J. Wadsworth, Homogeneous Deformation of Bulk Metallic Glasses, Scr. Mater., 2006, 54(3), p 387-392

24. S. Yoon, H.J. Kim, G. Bae, B. Kim, and C. Lee, Formation of Coating and Tribological Behavior of Kinetic Sprayed Fe-Based Bulk Metallic Glass, J. Alloys. Compd, 2011, 509(2), p 347-353

25. S. Yoon, G. Bae, Y. Xiong, S. Kumar, K. Kang, J.J. Kim, and C. Lee, Strain-Enhanced Nanocrystallization of a CuNiTiZr Bulk Metallic Glass Coating by a Kinetic Spraying Process, Acta Mater., 2009, 57(20), p 6191-6199

26. A. List, F. Gärtner, T. Schmidt, and T. Klassen, Impact Conditions for Cold Spraying of Hard Metallic Glasses, J. Therm. Spray Technol., 2012, 21(3-4), p 531-540

27. P.D. Olmsted, Perspectives on Shear Banding in Complex Fluids, Rheol Acta, 2008, 47(3), p 283-300

28. A. Concustell, J. Henao, S. Dosta, N. Cinca, I.G. Cano, and J.M Guilemany, On the Formation of Metallic Glass Coatings by Means of Cold Gas Spray Technology, J. Alloys Compd, 2015, 651, p 764-772 
29. J. Henao, A. Concustell, I.G. Cano, N. Cinca, S. Dosta, and J.M. Guilemany, Influence of Cold Gas Spray Process Conditions on the Microstructure of Fe-Based Amorphous Coatings, J. Alloys Compd, 2015, 622, p 995-999

30. J.W. Christian, The Theory of Transformations in Metals and Alloys, 2nd ed., Pergamon, Oxford, 1975

31. K. Kim, M. Watanabe, and S. Kuroda, Bonding Mechanisms of Thermally Softened Metallic Powder Particles and Substrates Impacted at High Velocity, Surf. Coat. Technol., 2010, 204(14), p 2175-2180

32. S. Yin, X.F. Wang, W.Y. Li, and X.P. Guo, Examination on Substrate Preheating Process in Cold Gas Dynamic Spraying, $J$. Therm. Spray Technol., 2011, 20(4), p 852-859

33. K. Yokoyama, M. Watanabe, S. Kuroda, Y. Gotoh, T. Schmidt, and F. Gärtner, Simulation of Solid Particle Impact Behavior for Spray Processes, Mater. Trans., 2006, 47(7), p 1697-1702

34. M. Grujicic, J.R. Saylor, D.E. Beasley, W.S. DeRosset, and D. Helfritch, Computational Analysis of the Interfacial Bonding Between Feed-Powder Particles and the Substrate in the ColdGas Dynamic-Spray Process, Appl. Surf. Sci., 2003, 219(3), p 211-227

35. D. Zhang, P.H. Shipway, and D.G. McCartney, Cold Gas Dynamic Spraying of Aluminum: the Role of Substrate Characteristics In Deposit Formation, J. Therm. Spray Technol., 2005, 14(1), p 109-116

36. P.C. King, G. Bae, S.H. Zahiri, M. Jahedi, and C. Lee, An Experimental and Finite Element Study of Cold Spray Copper Impact onto Two Aluminum Substrates, J. Therm. Spray Technol., 2010, 19(3), p 620-634

37. T. Marrocco, D.G. McCartney, P.H. Shipway, and A.J. Sturgeon, Production of Titanium Deposits by Cold-Gas Dynamic Spray: Numerical Modeling and Experimental Characterization, J. Therm. Spray Technol., 2006, 15(2), p 263-272

38. X.K. Suo, M. Yu, W.Y. Li, M.P. Planche, and H.L. Liao, Effect of Substrate Preheating on Bonding Strength of Cold-Sprayed Mg Coatings, J. Therm. Spray Technol., 2012, 21(5), p 1091-1098

39. M. Grujicic, C.L. Zhao, W.S. DeRosset, and D. Helfritch, Adiabatic Shear Instability Based Mechanism for Particles/ Substrate Bonding in the Cold-Gas Dynamic-Spray Process, Mater. Des., 2004, 25(8), p 681-688

40. L. Ajdelsztajn, E.J. Lavernia, B. Jodoin, P. Richer, and E. Sansoucy, Cold Gas Dynamic Spraying of Iron-Base Amorphous Alloy, J. Therm. Spray Technol., 2006, 15(4), p 495-500

41. S. Yoon, C. Lee, H. Choi, H. Kim, and J. Bae, Impacting Behavior of Bulk Metallic Glass Powder at an Abnormally High Strain Rate During Kinetic Spraying, Mater. Sci. Eng., 2007, 449, p 911-915

42. http://rsbweb.nih.gov/ij/index.html Accessed 04 Feb 2016

43. U. Prisco, Size-Dependent Distributions of Particle Velocity and Temperature at Impact in the Cold-Gas Dynamic-Spray Process, J. Mater. Process. Technol., 2015, 216, p 302-314

44. http://www.matweb.com/. Accessed 04 February 2016
45. M.A. Munoz-Morris, S. Surinach, M. Gich, M.D. Baró, and D.G. Morris, Crystallization of a Al-4Ni-6Ce Glass and its Influence on Mechanical Properties, Acta Mater., 2003, 51(4), p $1067-1077$

46. J. Wu, H. Fang, S. Yoon, H. Kim, and C. Lee, The Rebound Phenomenon in Kinetic Spraying Deposition, Scr. Mater., 2006, 54(4), p 665-669

47. A. List, F. Gärtner, T. Mori, M. Schulze, H. Assadi, S. Kuroda, and T. Klassen, Cold Spraying of Amorphous Cu50Zr50 Alloys, J. Therm. Spray Technol., 2015, 24(1-2), p 108-118

48. S. Yoon, C. Lee, H. Choi, and H. Jo, Kinetic Spraying Deposition Behavior of Bulk Amorphous Nitizrsisn Feedstock, Mater. Sci. Eng., 2006, 415(1), p 45-52

49. A.L. Yarin, Drop Impact Dynamics: Splashing, Spreading, Receding, Bouncing, Annu. Rev. Fluid Mech., 2006, 38, p 159-192

50. X. Zhou, X. Wu, S. Mou, J. Liu, and J. Zhang, Simulation of Deposition Behavior of Bulk Amorphous Particles in Cold Spraying, Mater. Trans., 2010, 51(10), p 1977-1980

51. S.H. Kang, J.H. Lee, J.S. Cheon, and Y.T. Im, The Effect of Strain-Hardening on Frictional Behavior in Tip Test, Int. J. Mech. Sci., 2004, 46(6), p 855-869

52. J.R. Davis, Tensile testing, chapter 7, 2nd ed., ASM interantional, Ohio, 2004

53. A. McDonald and S. Chandra, Kinematic Viscosities of HighTemperature Materials Used in Plasma Spraying, J. Am. Ceram. Soc., 2011, 94(6), p 1865-1871

54. H. Chiriac, M. Tomut, C. Naum, F. Necula, and V. Nagacevschi, On the Measurement of Surface Tension for Liquid Fesib GlassForming Alloys by Sessile Drop Method, Mater. Sci. Eng., 1997, 226, p 341-343

55. X. Chen and J.W. Hutchinson, Particle Impact on Metal Substrates with Application to Foreign Object Damage to Aircraft Engines, J. Mech. Phys. Solids, 2002, 50(12), p 2669-2690

56. R. Probstein, Physicochemical Hydrodynamics: An Introduction, Chapter 9, Wiley, New York, 2005, p 286

57. P. Gould, Introduction to Linear Elasticity, Chapter 3, Springer Science \& Business Media, Berlin, 2013, p 64-65

58. M. Fukumoto, H. Wada, K. Tanabe, M. Yamada, E. Yamaguchi, A. Niwa, and M. Izawa, Effect of Substrate Temperature on Deposition Behavior of Copper Particles on Substrate Surfaces in the Cold Spray Process, J. Therm. Spray Technol., 2007, 16(56), p 643-650

59. M.D. Demetriou and W.L. Johnson, Shear Flow Characteristics and Crystallization Kinetics During Steady Non-Isothermal Flow of Vitreloy-1, Acta Mater., 2004, 52(12), p 3403-3412

60. M.A. Meyers, V.F. Nesterenko, J.C. LaSalvia, and Q. Xue, Shear Localization in Dynamic Deformation of Materials: Microstructural Evolution and Self-Organization, Mater. Sci. Eng, 2001, 317(1), p 204-225

61. F. Spaepen, A Microscopic Mechanism for Steady State Inhomogeneous Flow in Metallic Glasses, Acta Metall., 1977, 25(4), p 407-415 